\title{
Análisis funcional de la disartria en un caso de esquizofrenia para- noide: Aproximación desde la Lingüística Clínica
}

\author{
JUAN LUIS JIMÉNEZ RUIZ \\ Universidad de Alicante \\ Facultad de Filosofia y Letras \\ Apdo. de correos, 99 \\ 03080 Alicante (España) \\ E-mail: jimenez@ua.es
}

\author{
Verónica SÁNChez Climent \\ Universidad de Alicante \\ Facultad de Filosofia y Letras \\ Apdo. de correos, 99 \\ 03080 Alicante (España) \\ E-mail: veronica.sanchez@gmail.com
}

\section{ANÁLISIS FUNCIONAL DE LA DISARTRIA EN UN CASO DE ES- QUIZOFRENIA PARANOIDE: APROXIMACIÓN DESDE LA LIN- GÜÍSTICA CLÍNICA}

RESUMEN: El lenguaje y sus alteraciones han sido estudiados desde muchos ámbitos disciplinarios. La Lingüística Clínica es un nuevo ámbito de aplicación del conocimiento lingüístico. En este trabajo presentamos el caso clínico de un paciente esquizofrénico que además sufre una disartria. A lo largo del ensayo nos ocuparemos de explicar en qué consisten estas dos patologías, el interés que nos suscitan desde una aproximación lingüística y desarrollaremos el caso arriba mencionado, nues tra intervención y la creación de un plan de rehabilitación para que el paciente pueda mejorar.

PALABRAS CLAVES: disartria; historia clínica; esquizofrenia; Lingüística Clínica.

SUMARIO: 1. Introducción. 2. La disartria en el marco teórico de la Lingüística Clínica. 3. La disartria en un caso de esquizofrenia paranoide. 4. Metodología. 5. Resultados. 6. Propuesta de intervención. 7. Conclusión.

\section{FUNCTIONAL ANALYSIS OF DYSARTHRIA IN A CASE OF PARANOID SCHIZOPHRENIA: APPROXIMATION FROM CLINICAL LINGUISTICS}

ABSTRACT: Language and its disorders have been studied from many disciplinary areas. Clinical Linguistics is a new field of Applied Linguistics. In the present work we present a clinical record from a schizophrenic patient with dysarthria. We will explain what these pathologies consist in, the interest from a linguistic approach and we will also develop the case mentioned above, our intervention and the creation of a rehabilitation plan for the patient's recovery.

KEY WORDS: Dysarthria; Clinical History; Schizophrenia; Clinical Linguistics.

SUMMARY: 1. Introduction. 2. Dysarthria in the theoretical framework of clinical linguistics. 3. Dysarthria in a case of paranoid schizophrenia. 4 Metodology. 4. Results. 5. Intervention proposal. 6. Conclusion.
ANALYSE FONCTIONELL DE LA DYSARTHRIE DANS UN CAS DE SCHIZOPHRÉNIE PARANOÏDE: APPROXIMATIONS DE LA LINGUISTIQUE CLINIQUE

RÉSUMÉ: Le langage et ses alterations ont été étudiés depuis nombreux domaines disciplinaires. Linguistique Clinique est un nouveau domaine d'application des connaissances linguistique. Dans ce travail nous presentons le cas clinique d'un patient schizophrène qui, en plus, souffre d'une dysarthrie. Au fil de ces pages nous nos occuperons d'expliquer ces deux pathologies, l'intérêt que suscitent d'une approximation linguistique et nous développerons le cas mentioné, notre intervention et la création d'un plan de réhabilitation au fin que le patient puisse améliorer.

MOTS CLÉS: dysarthrie; cas clinique; schizophrénie; linguistique clinique.

SOMMAIRE: 1. Introduction. 2. La dysarthrie dans cadre théorique de la Linguistique Clinique. 3. La dysarthrie dans un cas de schizophrénie paranoïde. 4. Méthodologie. 4 Résultats. 5. Proposition d'intervention. 6. Conclusion.
Fecha de Recepción Fecha de Revisión Fecha de Aceptación Fecha de Publicación
$16 / 03 / 2018$

$28 / 10 / 2018$

$01 / 11 / 2018$

$01 / 12 / 2018$ 


\title{
Análisis funcional de la disartria en un caso de esquizofrenia para- noide: Aproximación desde la Lingüistica Clínica
}

\author{
JUAN LUIS JiMÉNEZ RUIZ \& VERÓNICA SÁNCHEZ CLIMENT
}

\section{INTRODUCCIÓN}

En el presente trabajo analizaremos el caso clínico de un paciente diagnosticado de esquizofrenia que padece disartria, trastorno articulatorio de la programación motora del habla, cuya etiología se debe a una lesión cerebral. Nos interesa especialmente centrarnos en la disartria como conducta verbal problemática presente en la esquizofrenia que padece el paciente ${ }^{1}$, realizando una aproximación desde el ámbito lingüístico, con el fin de justificar la importancia del lingüista clínico, parcialmente desconocida hoy en día en nuestro país ${ }^{2}$, frente a este tipo de casos, concienciando al lector sobre la labor que estos profesionales podrían desempeñar en la mejora de la calidad asistencial de determinados pacientes psiquiátricos con déficits lingüísticos, defendiendo, así, la necesidad de que pudiesen formar parte de los equipos interdisciplinarios que tratan estos trastornos.

De hecho, la Lingüística Clínica es una rama de la Lingüística aplicada que surge, entre otras razones, debido a la creciente necesidad de explorar los procesos biológicos que se dan en el ser humano a la hora de comunicarse, con objeto de evaluar, clasificar e intervenir en los problemas de déficits del lenguaje y el habla.

Ya lo expresó Crystal al afirmar que:

La Lingüística Clínica es la aplicación de las ciencias lingüísticas al estudio de la discapacidad del lenguaje en todas sus formas. La etiqueta 'discapacidad' no debe ser interpretada de manera demasiado estricta. Se refiere a alguien cuya capacidad de usar el lenguaje es lo suficientemente subdesarrollada o deteriorada como para requerir un tratamiento o enseñanza especiales. Es uno de los varios términos que se han utilizado para caracterizar las dificultades involucradas: otros incluyen trastorno, disfunción, perturbación, desventaja, déficit, privación y discapacidad. Estas etiquetas difieren en sus matices y expectativas, y varian en su posición como términos con estatus profesional; algunos, de hecho, están emocionalmente cargados y son políticamente sensibles. Pero desde un punto de vista clínico-lingüístico, lo importante es la forma en que indican la existencia de un dominio del uso anormal del lenguaje que, en su rango y complejidad, justifica la investigación por parte del especialista (Crystal, 2001: 673).

Como pone de relieve Crystal, la Lingüística Clínica es la disciplina específica encargada del estudio de las patologias que afectan tanto al lenguaje

\footnotetext{
${ }^{1}$ Evidentemente, al margen de otros problemas que la esquizofrenia pueda provocar en el habla, tales como la falta de modulación en la voz y los movimientos repetitivos de la región orolingual (morderse los labios, sacar la lengua, etc.), en la mayoria de las veces causados por la medicación neuroléptica o antipsicótica administrada en este tipo de patología.

2 Tal y como reconoce Fernández Pérez (2014: 39) y es común en las dinámicas de sedimentación de áreas científicas, "las indagaciones en Lingüística Clínica son previas al reconocimiento y a la institucionalización del campo".
} 
como al habla y, por ende, el lingüista clínico, debe ser el especialista de este campo, encargado de desarrollar y proponer el plan de intervención para las personas que padezcan cualquier disfunción en el lenguaje o en el habla. En un equipo interdisciplinar integrado por neurólogos, psicólogos (o neuropsicólogos) y logopedas, el lingüista clínico sería el encargado de diseñar el plan de actuación lingüística, que llevaria a la praxis el logopeda, tras los estudios pertinentes llevados a cabo por los especialistas sanitarios, siendo el auténtico nexo de unión imprescindible entre los miembros del equipo multidisciplinar. Por tanto, el lingüista estudia la conducta verbal problemática y propone el procedimiento de intervención ajustado a las necesidades del paciente que, posteriormente, el rehabilitador puede llevar a cabo.

Por ello, desde la Lingüística Clínica estudiaremos el caso de un paciente que padece esquizofrenia paranoide, acompañada además de disartria, que es la patología que desde nuestro ámbito disciplinario nos interesa especialmente. La razón se debe a que los pacientes que padecen disartria y los que padecen esquizofrenia muestran unos rasgos problemáticos en el habla muy parecidos.

En este sentido, nuestra línea argumental plantea las siguientes problemáticas o preguntas de investigación: primero, la que gira en torno a la precisión conceptual de lo que es la disartria, sus tipos, la esquizofrenia paranoide y el interés que suscita dentro del campo de estudio de la Lingüística Clínica; segundo, la que se plantea la forma en la que hemos abordado el estudio del caso clínico y las conclusiones a las que hemos llegado. Y, finalmente, la que se interroga sobre el plan de rehabilitación que proponemos, justificando así la función del lingüista clínico en este tipo de casos y su intervención en un centro psiquiátrico.

Desde el planteamiento metodológico, para realizar esta investigación y cumplir los objetivos propuestos, además del uso y consulta de libros, artículos científicos y revistas especializadas, hemos utilizado el Programa Integrado de Exploración Neuropsicológica (PIEN), Test-Barcelona (Peña-Casanova, 1990). Tanto el manual como los test de actividades utilizados nos han sido de gran utilidad, puesto que, gracias a su uso, hemos podido evaluar al paciente.

Nuestro paciente se encuentra ingresado en la unidad psiquiátrica del centro Dr. Esquerdo de San Juan de Alicante. Debemos señalar que la colaboración por parte del personal del hospital psiquiátrico ha sido imprescindible para que este trabajo se pudiese llevar a cabo. Entre los materiales utilizados, hemos requerido el uso de un dispositivo de grabación de voz en formato MP3 (con el consentimiento tanto del paciente como del centro) y un cronómetro para controlar el tiempo de reacción y respuesta.

Asimismo, debemos advertir que el caso que nos ocupa entraña cierta dificultad, ya que, además de la escasez de datos lingüísticos sobre este tipo de patología (Green, Carmichael y Hatzis, 2003: 1189 y ss.), el trabajo con 
un paciente que, además del propio trastorno lingüístico, padece una enfermedad mental como es la esquizofrenia paranoide, nos obliga a realizar una intervención que perturbe al sujeto lo menos posible, puesto que, a pesar de estar controlado y estable en el momento de la investigación, su comportamiento podia resultar impredecible.

El paciente, sin embargo, se encontró estable durante el proceso de recogida de datos, presentando conciencia de su propia enfermedad y mostrándose colaborador en todo momento. A pesar de su disfunción en el habla, se entiende lo que dice ${ }^{3}$, es capaz de explicar lo que le sucede, de responder a nuestras preguntas, y de contarnos, incluso bromeando, episodios de su vida, muchos relacionados con el accidente cerebrovascular que le produjo la disartria. Es una persona ocupada, ya que en el centro en el que se encuentra participa en los talleres de terapia. Hemos podido acompañarle en más de una ocasión, pudiendo de esta manera, observarle dentro de su ámbito social, evitando así la 'paradoja del observador'4, y explorar sus síntomas lingüísticos de manera general.

A lo largo de varios meses le hemos realizado una serie de entrevistas informales, con las que se estableció una relación terapéutica favorable para la evaluación, y otras más formales, en las que recogimos información detallada sobre los déficits lingüísticos que presentaba, aplicando los test y las pruebas del Test-Barcelona (Peña-Casanova, 1990), con la intención de valorar específicamente su expresión oral, comprensión oral, escritura y lectura. Realizamos un análisis biográfico del paciente y un análisis retrospectivo de las conductas lingüísticas problemáticas.

Todo ello queda estructurado en el artículo que presentamos en cinco partes. En la primera de ellas, presentamos la disartria en el marco teórico y metodológico de la Lingüística Clínica, estudiando su etiopatogenia, clasificación tipológica, sintomatología, evaluación y posible intervención. A continuación, en la segunda, analizamos la disartria en el caso de la esquizofrenia paranoide. En la tercera parte (la propiamente metodológica) analizamos el caso clínico, presentando e identificando al sujeto y los problemas que presenta; resumimos la historia del problema y realizamos el análisis funcional de las conductas lingüísticas problemáticas, para terminar con la precisión de las distintas áreas de exploración lingüísticas. En la cuarta parte precisamos los resultados obtenidos y, en la quinta y última, señalamos la propuesta de intervención correspondiente. Finalmente, terminamos con las conclusiones a las que hemos llegado tras el estudio del caso clínico.

Comencemos, pues, con la presentación de la disartria en el marco teórico y metodológico de la Lingüística Clínica, señalando, a continuación, su

\footnotetext{
${ }^{3}$ Teniendo en cuenta, obviamente, el tipo de esquizofrenia que padece.

${ }^{4}$ La manera de actuar de un sujeto que está siendo observado cambia inevitablemente al ser este consciente de que se le está evaluando, pero a su vez, la necesidad del observador de permanecer a su lado, juzgándole, es también inevitable. Por ello siempre se debe buscar la manera más adecuada de hacer creer que el observador es un mero integrante del grupo, es decir, uno más (Labov, 1972: 209).
} 
etiopatogenia, las principales taxonomias que se han realizado, su sintomatología y, finalmente, su evaluación y posible intervención.

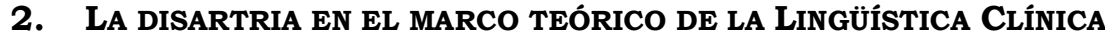

Como afirmamos con anterioridad, debemos situar nuestro trabajo en el ámbito de la Lingüística Clínica, ya que es la rama de la Lingüística encargada de estudiar los trastornos de la comunicación. Ya Perkins y Howard afirmaron que la Lingüística Clínica era la disciplina que estudiaba las teorías lingüísticas y, además, la aplicación de estas al tratamiento de las patologias del lenguaje (Perkins y Howard, 1995: 11). Por ello, podemos decir que la Lingüística Clínica se afianza en el sentido señalado; esto es, como la aplicación de los conocimientos, las técnicas y los procedimientos de la Lingüistica al ámbito de las patologías del lenguaje con la finalidad de describir la comunicación patológica y contribuir a su terapia (Otero, 2002: 757). Serra y Veyrat (2005: 9) amplían la definición de nuestra disciplina al caracterizarla a partir de sus objetivos; a saber, por un lado, el conocimiento, descripción y análisis de los déficits lingüísticos; y, por otro, el desarrollo de propuestas teórico-prácticas basadas en el principio de la capacidad del sistema lingüístico para recuperar o habilitar el uso deteriorado del lenguaje. También Garayzábal y Otero (2005: 166), la caracterizan ya como la disciplina que se preocupa directamente de aspectos relacionados con las alteraciones del lenguaje, desde una postura descriptiva, identificando y dando sentido a los datos observados tanto en niños como en adultos. Es, por ello, la aplicación de la ciencia lingüística al estudio de las discapacidades comunicativas en todas sus formas, entendiendo por discapacidad un subdesarrollo de la habilidad para usar el lenguaje que necesita un tratamiento especial por parte de un especialista (Crystal, 2001: 673). La Lingüística Clínica es, por tanto, un nuevo ámbito de estudio, caracterizado por adoptar un enfoque integrador y multidisciplinar para dar cuenta de los problemas relativos a la forma y función comunicativa del ser humano, impidiendo su interacción con los demás por inhibición, ausencia, distorsión, divergencia o deterioro de su habilidad lingüística. Su objetivo no es, pues, la rehabilitación del paciente, sino el análisis y descripción del problema lingüístico con el fin de ayudar a su mejora (Garayzábal y Otero, 2005: 178).

Por ello, los conocimientos que un especialista que interviene en problemas de la comunicación, lengua y habla debe poseer permiten crear un perfil lingüístico del paciente a partir de una muestra representativa de su habla en la que se reflejarán las habilidades y las dificultades. Dicho de otra forma: el trabajo clínico no es separable del trabajo científico realizado por los lingüistas (Tobin, 2002: 17). En este sentido, el lingüista tiene que analizar el problema lingüístico y facilitar al terapeuta del lenguaje los datos necesarios para ayudar a la mejora del paciente (Ball y Müller, 2013: 32).

$\mathrm{Y}$, siguiendo esta dirección, el primer paso consiste en la precisión objetual del concepto de disartria. 
Dentro de las alteraciones fonéticas de causa orgánica, podemos diferenciar, siguiendo a Caballo y Simón (2001: 98), aquellas cuyo origen está relacionado, bien con anomalias en las estructuras periféricas implicadas en la producción del habla, como una mala oclusión dental, la existencia de frenillo lingual, malformaciones, labio leporino, etc. (conocidas como disglosias), o aquellas cuyo origen está relacionado con alteraciones en el movimiento y coordinación de los músculos requeridos para hablar a consecuencia de lesiones en el sistema nervioso (las llamadas disartrias).

Desde que ya en 1956 Alajouanine las caracterizara como dificultad de expresión oral del lenguaje, debida a trastornos del tono y movimiento de los músculos fonatorios, secundarios a lesiones del sistema nervioso (Alajouanine, 1956: 1-28), las definiciones se han ido sucediendo hasta precisarse como

Trastorno motor del habla de origen neurológico que está caracterizado por lentitud, debilidad, imprecisión, incoordinación, movimientos involuntarios y/o alteración del tono de la musculatura implicada en el habla. En consecuencia, la disartria implica una alteración de la articulación de la palabra (González y Bevilacqua, 2012: 299).

Se trata, por tanto, de una patologia de origen neurológico producida por la afectación del sistema nervioso central y/o periférico que provoca alteraciones en la ejecución del movimiento necesario para hablar (Melle, 2003: 21); dicho de otro modo, de una alteración de la articulación y expresión del habla que obedece a trastornos del tono y movimiento de los músculos fonatorios secundarios a lesiones del sistema nervioso central (Perelló, 1990: 4) o a enfermedades de los nervios o músculos de la lengua, faringe y laringe, responsable del habla (Belloch, Sandin y Ramos, 2008: 263).

Según Gallardo y Gallego (1995), la disartria es una alteración de la articulación producida por lesiones en el sistema nervioso central, así como por enfermedades de los nervios o de los músculos de la lengua, faringe y laringe, responsables del habla. León-Carrión, Viñals, Vega y Domínguez-Morales (2001: 35) la definen, a su vez, como un trastorno que cursa con lesión cerebral y que afecta a la expresión oral del habla, con alteraciones en la movilidad de los órganos fonoarticuladores (labios, lengua, mandíbula, velo del paladar, laringe, faringe) y al correcto funcionamiento de los mecanismos respiratorios, fonatorios, articulatorios y prosódicos.

Como podemos observar, todas las definiciones dadas tienen en común la causa (origen neurológico) y los problemas que la disartria provoca en el habla 5 . En este sentido, la principal limitación del paciente disártrico consiste en la reducción en la inteligibilidad de su habla, es decir, del grado en

\footnotetext{
5 De hecho, queda patente, aunque no sea de manera explícita, la importancia en la práctica clínica de la distinción entre los trastornos del habla y los trastornos del lenguaje debido a la gran proximidad semiológica que poseen ambos conceptos (Barrueco et alii, 1990: 152). En este sentido, debemos precisar que han sido los estudios lingüísticos los que han aportado la clara diferenciación conceptual que ha permitido a estudiosos de la práctica clínica diferenciar entre
} 
que su mensaje intencionado es recuperado por el oyente, por lo que la medida de la inteligibilidad del habla resulta ser de gran utilidad para el diagnóstico, terapia e investigación (Delgado Hernández, 2010: 175).

En suma, se trata, por tanto, de una articulación imperfecta del habla debido a alteraciones del control muscular (DSM IV: 781).

A continuación, explicaremos su etiopatogenia, clasificación tipológica y sintomatología.

\subsection{ETIOPATOGENIA}

Aunque el lenguaje y el habla, y sus trastornos en general, deben ser estudiados en términos de forma, uso y contenido, no debemos olvidar el criterio etiológico, debido a que algunos problemas se presentan aislados, pero muchos otros, asociados a problemas físicos, sensoriales, neurológicos y ambientales (Puyuelo y Rondal, 2003: 103). En el caso de las disartrias, pueden estar producidas por distintas causas. La causa principal es un daño o lesión cerebral, quedando afectados los músculos que intervienen en el habla. La disartria puede aparecer a cualquier edad siempre que se den las condiciones para que esta se produzca. A continuación, veremos algunos ejemplos de estos daños y enfermedades que pueden causar la disartria (Perelló, 1990: 5-6):

1. Lesión cerebral: alteración en el tejido cerebral, producto de accidente vascular, traumatismo, enfermedad o proceso degenerativo. En este caso la lesión produciría una alteración en el movimiento de los músculos de la región oro-lingual, causando en el paciente una rigidez que le imposibilitaría la articulación.

2. Tumor cerebral: grupo de células anormales que crece en el cerebro o alrededor de él. Los tumores pueden destruir directamente las células sanas del cerebro. También pueden dañarlas indirectamente por invadir otras partes del cerebro y causar inflamación, edema cerebral y presión dentro del cráneo. En este caso, ocurriría lo mismo que en la lesión cerebral.

3. Demencia: desorden del cerebro que es caracterizado por la pérdida y la dificultad de memoria. Es causada por problemas con los vasos sanguíneos que alimentan el cerebro.

el habla, como "expresión articulatoria y sonora del lenguaje" y el lenguaje como "sistema universal para todos los que comparten un código de comunicación" (Málaga et alii, 2004: 82). Así, los trastornos del habla tienen lugar cuando se ve afectado únicamente el nivel fonético-fonológico a causa de un mal funcionamiento de los mecanismos perceptivo-motores de la articulación del habla, generando problemas para componer un mensaje oral produciendo los sonidos en la palabra (Montfragüe García-Mateos, 2010: 76); por el contrario, los trastornos del lenguaje evidencian limitaciones en la capacidad lingüística del sujeto (Gorospe et alii, 1997: 50). De hecho, es importante desde el ámbito clínico, como ya reconociera Crystal, 1993: 66, la distinción entre Fonética, como estudio de los sonidos humanos y Fonología cómo análisis de la organización de estos sonidos, ya que es posible que haya trastornos que sólo afecten al sistema fonológico del habla de una persona, permaneciendo las capacidades fonéticas intactas. 
4. Enfermedad degenerativa: se origina por la alteración anatómica y funcional de los tejidos de cualquier órgano, aparato o sistema del organismo. Dos ejemplos muy conocidos de enfermedades degenerativas son el Parkinson y el Alzheimer, que afectan al sistema nervioso central.

5. Esclerosis múltiple: enfermedad progresiva del sistema nervioso central que provoca lesiones múltiples en la mielina que recubre los axones de las neuronas y constituye la sustancia blanca, en forma de placas diseminadas; se manifiesta con diversos sintomas como la parálisis de las extremidades inferiores, hormigueo, pérdida de la sensibilidad, etc. La parálisis del rostro sería una de las causas para la aparición de la disartria.

6. Enfermedad de Parkinson: enfermedad crónica y degenerativa del sistema nervioso que se caracteriza por falta de coordinación, rigidez muscular y temblores.

7. Accidente cerebrovascular: como es el caso de nuestro paciente, un accidente cerebrovascular sucede cuando el flujo de sangre a una parte del cerebro se detiene. Si el flujo sanguíneo se detiene por más de pocos segundos, el cerebro no puede recibir nutrientes y oxígeno. Las células cerebrales pueden morir, lo que causa daño permanente. En el caso de nuestro paciente, la disartria que padece viene provocada por un ictus cerebral, es decir, un accidente cerebrovascular.

8. Traumatismo facial o cervical: lesión grave en el cuello o en el rostro, bien sea por golpes contusos o por heridas penetrantes, que en este caso producirian la parálisis o la imposibilidad del movimiento de los músculos faciales.

9. Parálisis cerebral: grupo de trastornos que pueden comprometer las funciones del cerebro y del sistema nervioso provocando los problemas en el habla en el caso que estamos estudiando (disartria).

10. Miastenia gravis: enfermedad neuromuscular de origen autoinmune caracterizada por una gran debilidad de la musculatura y propensión a la fatiga, especialmente en la cara y en el cuello.

11. También pueden darse otras causas como los efectos secundarios de medicamentos que actúan sobre el sistema nervioso central.

Si nos fijamos, no importa cuál sea el foco, siempre se van a dar las mismas condiciones en la región facial/oro-lingual para que exista un problema de disartria: rigidez, parálisis o imposibilidad de movimiento en la zona.

\subsection{Clasificación tipológica}

El siguiente paso consiste en la precisión taxonómica. Para ello, conviene señalar que, aunque la clasificación de las disartrias se haya realizado atendiendo a diferentes criterios; a saber, el lugar en el que se produzca la lesión, los sintomas que la caracterizan, y la toma articulatoria, existe un cierto 
acuerdo en diferenciar cuatro tipos diferentes: la flácida, la espástica, la atáxica y la hiper/hipocinética (Theodoros, Murdoch y Chenery, 1994: 101 y ss.; Gallardo y Gallego, 1995; Duffy, 2005: 109 y ss.). A continuación, haremos un repaso por cada una de las clasificaciones, explicando en qué consisten y cómo afectan a la persona que las padece.

Comenzando por el lugar de la lesión (Enderby, 2013: 273 y ss.), las disartrias se clasifican en:

1. Disartria por trastornos de la motoneurona superior (disartria espástica).

2. Disartria por trastornos de la motoneurona inferior (disartria flácida).

3. Disartria por trastornos cerebelosos (disartria atáxica).

4. Disartria por trastornos extrapiramidales (disartria discinética).

5. Disartria por trastornos de múltiples sistemas motores (disartria mixta).

Atendiendo ahora a sus características sintomatológicas (Theodoros, Murdoch y Chenery, 1994; 101 y ss.; Puyuelo, 1998: 263-279; González y Bevilacqua, 2012: 299-309), pueden ser también:

1. Disartria espástica: producida por trastornos de la motoneurona superior. La espasticidad se reconoce como una peculiar resistencia al movimiento pasivo de un grupo muscular, produciendo sonidos con mucha tensión muscular. El habla es lenta y parece surgir con esfuerzo, como si se produjera en contra de una gran resistencia.

2. Disartria flácida: producida, en este caso, por la lesión de algún componente de la motoneurona inferior, lo que supone la alteración del movimiento voluntario, automático y reflejo, produciendo flacidez y parálisis con disminución de los reflejos de estiramiento muscular. También puede producirse atrofia de las fibras musculares. En la articulación se produce un sonido con escasa tensión muscular.

3. Disartria atáxica: producida ahora por una afectación cerebelosa. El cerebelo es el que regula la fuerza, duración, dirección y velocidad de los movimientos originados en otros sistemas motores. La afectación del habla suele presentarse coincidiendo con lesiones cerebelosas bilaterales o generalizadas. Los músculos suelen estar hipotónicos y los movimientos son lentos e inapropiados en la fuerza, extensión, duración y dirección. Viene asociada a una disfunción laríngea que se manifiesta en una aspereza de la voz y una monotonía en el tono con pocas variaciones en la intensidad.

4. Disartria discinética: el sistema extrapiramidal es el encargado de regular el tono muscular necesario para mantener una postura o cambiarla. Organiza los movimientos asociados a la marcha y facilita el automatismo en los actos voluntarios que requieren destreza. Las manifestaciones extrapiramidales se manifiestan a menudo en forma de hipocinesia, apareciendo lentitud y limitación en la ejecución de los movimientos, disminución de los actos espontáneos y asociados, rigidez, temblor en reposo, así 
como pérdida de los aspectos automáticos del movimiento ${ }^{6}$, atetosis, temblor y distonía, en las que se producen movimientos anormales involuntarios. Aparece una articulación distorsionada, exceso prosódico, insuficiencia prosódica, estenosis fonatoria e incompetencia resonatoria.

5. Disartria mixta: finalmente, este tipo de disartrias poseen patrones de disfunción del habla que combinan las características de los sistemas motores implicados. Algunas de las enfermedades que se corresponden con este cuadro son la parálisis bulbar progresiva o enfermedad de la motoneurona ${ }^{7}$ y la esclerosis múltiple.

Finalmente, considerando ahora la toma articulatoria, pueden ser:

1. Disartria generalizada (trastornos en la articulación general y aislada).

2. Estado disártrico (toma articulatoria cambiante, variable por patología de base cambiante en el tiempo o que evoluciona por crisis).

3. Restos disártricos (trastornos en la articulación general y no en la aislada).

Como reconocen León-Carrión, Viñals, Vega y Domínguez-Morales (2001: 36), resulta muy complicado el encuadre del trastorno que presenta el sujeto en un único tipo de disartria ya que los pacientes comparten sintomas variados.

Por ello, y aunque todas las disartrias puedan ser secundarias a la parálisis cerebral infantil o a los traumatismos craneoencefálicos y su sintomatología más frecuente (Muñoz-Céspedes y Melle, 2003: 435 y ss.) pueda ser la siguiente: la imprecisión articulatoria por dificultades en el control y coordinación de los músculos de la lengua y/o de la fuerza en los labios, la hipernasalidad por dificultades en el cierre velofaringeo, las alteraciones en la coordinación respiratoria por mal control en la coordinación del movimiento

\footnotetext{
${ }^{6}$ Estas son las manifestaciones que se presentan en la enfermedad de Parkinson, pero también pueden presentarse síntomas hipercinéticos en patologías, como la corea de Huntington, grave y rara enfermedad neurológica, hereditaria y degenerativa.

7 "Las enfermedades de la neurona motora son un grupo de trastornos neurológicos progresivos que destruyen las neuronas motoras, las células que controlan la actividad muscular voluntaria esencial como hablar, caminar, respirar y tragar. Normalmente, los mensajes de las células nerviosas en el cerebro (llamadas neuronas motoras superiores) se transmiten a las células nerviosas en el tallo cerebral y la médula espinal (llamadas neuronas motoras inferiores) y de alli a los músculos particulares. Las neuronas motoras superiores dirigen a las neuronas motoras inferiores para producir movimientos como caminar y masticar. Las neuronas motoras inferiores controlan el movimiento de los brazos, las piernas, el tórax, la cara, el cuello y la lengua.

Cuando hay interrupciones en estas señales, los músculos no funcionan adecuadamente; el resultado puede ser el debilitamiento gradual, la emaciación, y tics incontrolables (llamados fasciculaciones). Cuando están afectadas las neuronas motoras superiores, las manifestaciones incluyen espasticidad o rigidez de los músculos de los miembros e hiperreactividad de los reflejos tendinosos como sacudidas de la rodilla y el tobillo. Finalmente, puede perderse la capacidad de controlar el movimiento voluntario. Estas enfermedades pueden heredarse o adquirirse" (NINDS- National Institute of Neurological Disorders and Stroke).
} 
de los músculos diafragmáticos, las alteraciones en la prosodia con prolongaciones inadecuadas entre las silabas o palabras, $y$, finalmente, las alteraciones en la fonación por hiper/hipofuncionalidad de la laringe; conviene precisar la sintomatología específica de cada tipo de disartria.

\subsection{SinTOMATOLOGÍA}

Como hemos expuesto, cada tipo de disartria tiene un origen y se produce debido a unas causas, siendo sus sintomas también diferentes (Perelló, 1990: 55); por ello, debemos precisar aquí los principales:

1. Disartria espástica: aquí, como hemos dicho, la afectación se produce en el nivel de la neurona motriz superior y sus caracteristicas son (Apepalen.cyl.com, 2017): resistencia al movimiento pasivo de un grupo muscular; emisión de frases cortas; debilidad y espasticidad en un lado del cuerpo, en los músculos distales de las extremidades, la lengua y los labios; articulación consonántica poco precisa y, a veces, con distorsiones vocálicas; reflejos de estiramiento muscular exagerados; disfunción articulatoria; lentitud en el habla; voz ronca; tono bajo y monótono; interrupciones tonales o de la respiración ocasionalmente.

2. Disartria flácida: en este caso la lesión está localizada en la neurona motriz inferior. Sus características y síntomas son (Apepalen.cyl.com, 2017): alteración del movimiento voluntario, automático y reflejo; flacidez y parálisis con disminución de reflejos musculares; articulación consonántica distorsionada; posible afectación de la musculatura respiratoria, lengua y movimientos del paladar; debilidad o fatiga; debilidad de las cuerdas vocales, paladar y laringe; alteraciones respiratorias (rápida y superficial); deglución dificultosa; producción excesiva de sonidos nasales; voz ronca y poco intensa.

3. Disartria atáxica: la afectación del cerebelo ocasiona la disartria atáxica. Es a partir de lesiones cerebelosas cuando se deduce que este órgano regula la fuerza, velocidad, duración y dirección de los movimientos ocasionados en otros sistemas motores, ya que estos se pierden. Sus sintomas son (Apepalen.cyl.com, 2017): disfunciones articulatorias mediante distorsiones; hipotonía de los músculos afectados; dirección, duración e intensidad de movimientos lentos e inapropiados en la fuerza; alteraciones prosódicas por énfasis en determinadas sílabas; posible irregularidad de los movimientos oculares; disfunción faríngea caracterizada por una voz áspera y una monotonía en el tono con escasas variaciones en la intensidad.

4. Disartria por lesiones en el sistema extrapiramidal: las hay de dos tipos (Apepalen.cyl.com, 2017); a saber,

4.1. Hipocinéticas, característica en la enfermedad de Parkinson, con los siguientes rasgos: movimientos lentos, limitados y rígidos; 
movimientos repetitivos en los músculos del habla; voz débil, articulación defectuosa, falta de inflexión; frases cortas; falta de flexibilidad y control de los centros faringeos; monotonía tonal; variabilidad en el ritmo articulatorio.

4.2. Hipercinéticas, con movimientos involuntarios irrelevantes y excesivos pudiendo afectar a la respiración, la deglución y la articulación a la vez siendo esto impredecible.

5. Disartria mixta: es la forma más compleja de disartria ya que los problemas que produce se dan por la combinación de dos o más tipos de disartria. (Apepalen.cyl.com, 2017).

\section{LA DISARTRIA EN UN CASO DE ESQUIZOFRENIA PARANOIDE}

Una vez que hemos presentado la conceptualización de la patología que es objeto de nuestro trabajo, debemos precisar ahora al estudio del caso que proponemos; esto es, el de un paciente con esquizofrenia paranoide que, además, padece una disartria debido a un ictus que sufrió hace unos años. Como veremos más adelante, el paciente era un hombre con esquizofrenia paranoide 'únicamente', hasta los 29 años, edad en la que padeció un ictus que le produjo la disartria que todavía padece.

La disartria, como hemos visto, es un trastorno de la programación motora del habla, producida por una lesión o daño cerebral, que presenta alteración en la articulación de las palabras. Es, quizá el más frecuente de estos trastornos, ya que representa alrededor de la mitad de los casos, y se manifiesta como una activación anómala de los músculos de las cavidades oral y faringea, y en algunos casos de la laringe, lo que trae consigo la articulación anormal de los sonidos del habla, aunque a veces puede afectarse concomitantemente la fonación y la prosodia, así como la respiración (Duffy, 2005: 69 y ss.).

En términos generales y a grandes rasgos, entre las características que puede presentar una persona con disartria se encuentran los cambios en el timbre de la voz, el 'arrastre' de las palabras o el habla escandida, es decir, a 'saltos' y con interrupciones, el habla muy baja, lenta y 'entre dientes', la movilidad limitada de la lengua, los labios y la mandíbula, la entonación y el ritmo anormales al hablar, ronquera, voz entrecortada y babeo o escaso control de la saliva. La disartria puede darse tanto en niños como en adultos, una vez que estos hayan adquirido ya el lenguaje, ya que el daño cerebral, necesario para que esta ocurra, puede producirse durante el parto o incluso, antes, durante o después de la gestación. Si es detectada por los profesionales y trabajada con tiempo, cabe la posibilidad de mejora de las capacidades comunicativas de la persona que la padece, sin importar la edad que tenga el paciente, la cual es fundamental para la creación del oportuno programa de rehabilitación (Urban et alii, 2006: 770-772). 
La esquizofrenia, por otro lado, es un trastorno mental grave que afecta a más de 21 millones de personas en todo el mundo. Se caracteriza por una distorsión del pensamiento, las percepciones, las emociones, el lenguaje, la conciencia de sí mismo y la conducta. Algunas de las experiencias más comunes son el hecho de oír voces y los delirios. La esquizofrenia es tratable, siendo eficaces la farmacoterapia y el apoyo psicosocial, según la O. M. S. Este tipo de pacientes relatan a menudo que 'han perdido el control sobre sus pensamientos', que 'se los han robado', que 'se los han impuesto', que 'son dirigidos por extraños poderes', etc. Muchas veces, incluso, están convencidos de que son ellos los que 'tienen poderes' (los conocidos como "trastornos del yo") (gofeminin.de $\mathrm{GmbH}, 2017$ ). Las personas que padecen esquizofrenia paranoide son propensas a perder el control con facilidad. Son impulsivos y suelen volverse agresivos, fruto de los delirios (tanto visuales como auditivos) que padecen también fácilmente, llegando incluso a agredir a sus más allegados. Muchos de ellos también presentan ideas de tipo referencial, es decir, se obsesionan con una persona e intentan 'defenderse' de ella (muchas veces agrediéndola o incluso intentándola matar). Esta patología no tiene cura, pero con el seguimiento pertinente por parte de profesionales cualificados, la medicación adecuada y un ambiente favorable para su mejora, el paciente puede llevar una vida estable y 'normal'. La esquizofrenia trae consigo alteraciones en el lenguaje, aunque podemos ver que, normalmente, los pacientes esquizofrénicos que se encuentran en tratamiento, suelen presentar problemas también en el habla, mostrando características y restos disártricos. Como señala Belinchón (1988: 232-258), hay tres tipos de observaciones clinicas:

1. Que el habla de los esquizofrénicos es poco fluida y ocasionalmente muestra alteraciones prosódicas que afectan a la entonación y velocidad.

2. Que el lenguaje esquizofrénico es perseverativo.

3. Que el lenguaje esquizofrénico es ininteligible, incoherente y/o difícil de comprender por el interlocutor.

Si enumeramos todas las distorsiones lingüísticas que existen y que se han detectado en la esquizofrenia podriamos citar las siguientes: pobreza tanto en el discurso, como en el contenido de éste, habla apresurada, logorrea $^{8}$, discurso divergente y tangencial ${ }^{9}$, neologismos, descarrilamiento ${ }^{10}$, incoherencia en el discurso, produciéndose aproximación de palabras y la llamada 'ensalada de palabras', asonancia y alteración, lenguaje prolijo, discurso circunstancial, pérdida del objetivo, saltos y cambios en el tema, olvido del tema, repetición inadecuada de palabras y/o morfemas, ecolalia ${ }^{11}$,

\footnotetext{
8 Empleo excesivo y desordenado de palabras al hablar.

${ }^{9}$ Habla distraida e irrelevante.

10 Falta de conexión o hilo conductor.

11 Repetición de frases y sonidos de forma involuntaria.
} 
bloqueo, discurso enfático, discurso autorreferencial ${ }^{12}$, parafasia fonémica ${ }^{13}$, parafasia semántica ${ }^{14}$, farfulleo, preferencia por la utilización del significado dominante de las palabras, rimas y aliteraciones no relacionadas con el tópico del discurso, emisión de palabras y/o frases que se asocian con otras anteriormente dichas pero que no son relevantes para el discurso, alteraciones de la sintaxis que afectan a la organización de las oraciones y/o los discursos, incapacidad aparente para darse cuenta de los errores lingüísticos cometidos, taquilalia ${ }^{15}$, palilalia ${ }^{16}$, kinesia paradojal $^{17}$, tono bajo, sin ritmo, sin enfatizar en ninguna palabra, discurso plano, alogia ${ }^{18}$, desorden en la creación de frases, pausas innecesarias, lentitud de producción... (Accatino, 2012: 1-8).

Tras haber precisado las características de la disartria y las características lingüísticas problemáticas en la esquizofrenia, proseguiremos con las semejanzas y las diferencias lingüísticas entre ambos trastornos. La disartria es un trastorno lingüístico que afecta únicamente al habla, mientras que la esquizofrenia, afecta al lenguaje y al habla. Como hemos podido senalar anteriormente, la disartria y la esquizofrenia comparten la gran mayoría de problemas en el habla, tales como el uso del tono bajo, la ausencia de ritmo, lentitud, alteración en la articulación de las palabras, falta de fuerza, debilidad, falta de coordinación, etc. La diferencia más notable entre estos dos trastornos es la intensidad con la que se presentan los problemas en el habla. En la disartria, este déficit se encuentra mucho más agravado que en el caso de la esquizofrenia y, por tanto, los problemas articulatorios se dan con más intensidad. Muchas veces, la rigidez en la región oro-lingual de las personas con disartria es apreciable, no siendo así en el caso de la esquizofrenia. Algunas de las alteraciones en el habla del paciente con esquizofrenia podrían deberse al uso de los neurolépticos o antipsicóticos, como veremos más adelante. También debemos recordar la diferencia entre las causas de ambas patologias. La disartria viene dada como causa secundaria a una lesión cerebral, siendo la esfera del habla la más afectada, mientras que la esquizofrenia consiste en la perturbación del curso del pensamiento, y los problemas que provoca en el habla son secundarios a la propia patologia.

\section{Metodología}

A continuación, debemos abordar en este apartado el aspecto puramente metodológico de nuestro trabajo. Una vez conceptualizado el objeto de estudio, se trata ahora de precisar los aspectos básicos que consideraremos en

\footnotetext{
12 Hablar sobre sí mismos.

13 Reemplazar unos fonemas por otros.

14 Reemplazar una palabra por otra del mismo campo semántico.

15 Habla extremadamente rápida.

16 Repetición de sílabas o frases.

17 Habla de pronto relativamente bien.

18 Habla vacía, proporciona poca información, aunque proporcione mucho contenido.
} 
el análisis de nuestro caso clínico. Comenzaremos reflexionando sobre la génesis de nuestra investigación y terminaremos señalando los principales puntos en los que organizamos nuestro trabajo metodológico.

Lo primero que debemos señalar tras lo anteriormente expuesto y sabiendo que los pacientes esquizofrénicos suelen padecer problemas en el habla derivados de la patología mental que sufren, es que centramos nuestra investigación en un paciente esquizofrénico que, además, padece un déficit lingüístico específico, en nuestro caso, la disartria, y que no muestra, por ello, únicamente los rasgos problemáticos en el habla que suelen padecer todos los pacientes esquizofrénicos.

Consecuentemente, el primer paso consistía en la localización del paciente que buscábamos. Nos pusimos en contacto con diversas unidades de Psiquiatría en Alicante, tales como la Unidad de Salud Mental del Hospital de San Juan de Alicante y la Unidad de Daño Cerebral del Hospital de San Vicente del Raspeig. En esos servicios no se nos pudo facilitar el contacto con ningún paciente por razones de confidencialidad clínica. Aunque este hecho supuso una dificultad inicial, decidimos acudir al Centro de internamiento psiquiátrico Dr. Esquerdo en San Juan de Alicante para exponerles nuestro proyecto y solicitar el permiso de la dirección para poderlo realizar en dicha institución ${ }^{19}$.

Mientras esperábamos la confirmación formal, se nos permitió la asistencia al hospital psiquiátrico con objeto de poder conocer a los pacientes y seleccionar aquel que fuese idóneo para nuestra investigación. Se nos habló de un paciente muy peculiar al que se referian como a un 'esquizofrénico que hablaba mal'; se trataba de un paciente que, tras un episodio cerebrovascular, comenzó a desarrollar problemas (que antes no tenía) en el habla. Había sido diagnosticado en principio de afasia mixta y, finalmente, de disartria.

Tras unas semanas de espera, recibimos los permisos formalmente y pudimos comenzar el trabajo con el paciente y con su historia clínica.

Conocimos al residente en un ambiente informal, saliendo a pasear con él, su grupo de compañeros y un trabajador del centro. El paciente se comportaba adecuadamente, encontrándose tranquilo y relajado, simpático y colaborador. Con estos paseos pudimos ir valorando el estado en el que se encontraba la disartria del paciente y, por tanto, comenzamos a elaborar nuestros planes para el estudio, organizando las pruebas y test que debíamos realizarle para conocer el grado de su disartria y poder, así, establecer el plan de rehabilitación que creyéramos oportuno.

\footnotetext{
${ }_{19}$ Para ello, el procedimiento consistió en la presentación por escrito de una solicitud formal a la Diputación Provincial de Alicante, órgano del que dependia funcionalmente el Centro psiquiátrico, explicando el contenido y el objetivo del trabajo que deseábamos realizar y comprometiéndonos a no revelar información privada ni a dar detalles sobre los pacientes con los que fuéramos a tratar. A continuación, hicimos lo mismo, pero esta vez dirigido al director del Ârea sanitaria del hospital al que estábamos intentando acceder.
} 
Decidimos realizar sesiones de duración variable, de entre 20 y 60 minutos, con el deseo de poder construir condiciones que facilitasen el trabajo lingüístico y que disminuyesen el posible cuadro ansiógeno asociado a las relaciones interpersonales.

Por ello, en los meses siguientes, le realizamos una serie de entrevistas semidirigidas y una serie de pruebas que nos iban a permitir analizar las conductas lingüísticas deficitarias, proporcionando siempre control al paciente sobre la programación y duración de las sesiones.

Dicho lo anterior, pasamos finalmente a concretar los principales puntos en los que organizamos nuestro trabajo metodológico; estos son, identificación de nuestro paciente, los problemas que presenta, la historia de estos problemas, el análisis y descripción de las conductas lingüísticas problemáticas y las áreas de exploración que realizamos.

\subsection{IDENTIFICACIÓN DEL SUJETO Y PROBLEMAS PRESENTADOS}

El sujeto cuyo caso clínico estudiamos y al que llamaremos D. T. M. a lo largo del trabajo para preservar su anonimato, es un varón de 40 años que se encuentra actualmente ingresado por orden judicial en el Centro psiquiátrico Dr. Esquerdo de San Juan de Alicante, con un diagnóstico de esquizofrenia paranoide además de una disartria como consecuencia de un accidente cerebrovascular. Ha cursado E.G.B. y ha trabajado como electricista y en el campo.

El residente se encuentra estable y orientado en las tres esferas. Es un paciente autónomo, puesto que realiza sus actividades cotidianas sin necesidad de supervisión; acude al programa de automedicación. La medicación somática también la realiza él solo ya que es diabético y con problemas vasculares. En el pasado tuvo problemas de obesidad mórbida llegando a pesar hasta $127 \mathrm{Kgs}$. de los cuales engordó 60 en menos de 3 años. También es exconsumidor de cocaina.

Socializa e interactúa de manera normal considerando las patologías que padece. A lo largo de la realización del estudio, no ha presentado ningún problema de interacción.

\subsection{HISTORIA DEL PROBLEMA}

El paciente, D. T. M., fue remitido por la U. S. M. del Hospital de Alfaz del Pi al Hospital de la Marina Baixa en diciembre de 2006 por presentar síntomas de ansiedad. El paciente, de 29 años en aquel momento, refirió entonces intensos sintomas de ansiedad somática y psíquica secundarios a la problemática con un vecino. Al no ser este el primer episodio de alucinaciones sufrido por el paciente y tras estudiar su situación, los especialistas concluyeron que el paciente padecía esquizofrenia paranoide, además de un trastorno de adaptación con estado de ánimo ansioso. El tratamiento que debía seguir consistió en la medicación con Tranxilium 10 por las mañanas, 
Tranxilium 50 por las noches, Risperdal Consta $50 \mathrm{mg}$. durante los 14 siguientes días, Zyprexa $5 \mathrm{mg}$. y Velotab y Risperdal $3 \mathrm{mg}$. por las noches. La evolución clínica fue bastante positiva ya que se disminuyeron los sintomas de ansiedad y el paciente fue capaz de tranquilizarse mostrándose correcto, colaborador, tranquilo, sin alteraciones en las conductas instintivas, sin alteraciones del contenido del pensamiento ni de la sensopercepción y negando cualquier ideación auto o heteroagresiva.

En agosto de 2009 el paciente acude a urgencias por un dolor torácico, pero los médicos, al observar el estado en el que se encontraba (el paciente hacía alusión a alucinaciones auditivas e ideas delirantes de contenido paranoide), procedieron a ingresarlo involuntariamente en la Unidad Hospitalaria de Psiquiatría. Allí, el paciente fue tratado de nuevo y volvió a adquirir conciencia del trastorno que padecía. Los médicos, tras cerciorarse de que el paciente estaba preparado para volver a su vida normal, le dieron el alta y le aumentaron la medicación (la dosis de Risperdal y la frecuencia de toma, además de añadirle un hipnótico cuando precisara).

Posteriormente, el paciente volvió a ser ingresado en urgencias en 2010 a causa de un infarto isquémico parietal izquierdo y cerebeloso derecho. Refería dificultad para hablar en los últimos cuatro dias, sin otra focalidad neurológica asociada y presentaba también cefalea leve, pero de características tensionales. En urgencias le realizaron una exploración fisica de la que destacaron una disminución de fuerza y de sensibilidad, desorientación y disartria. También se menciona en la historia clínica que alternaba episodios de uso normal del lenguaje con otros de disartria marcada y alteración de la nominación, con ausencia absoluta de lenguaje, pero sin problemas para obedecer órdenes, con los pares craneales normales y con fuerza, tono, sensibilidad y reflejos normales. Como pruebas complementarias le realizaron un T. A. C. cerebral en el que se apreciaba un área de hipodensidad parietal izquierda compatible con la lesión isquémica en evolución, sin lesiones hemorrágicas agudas y con el sistema ventricular centrado y sin efecto masa sobre él. Se le realizó también otro T. A. C. craneal sin contraste intravenoso en el que pudo observarse un área de isquemia subaguda parietal izquierda en el territorio posterior de A. C. M. izquierda, objetivando una tenue hiperdensidad laminar subyacente en relación con los cambios incipientes de transformación hemorrágica, sin evidencia de desplazamiento significativo de línea media ni efecto masa. Se encontró también un pequeño foco hipodenso en el hemisferio cerebeloso derecho de probable origen isquémico crónico. Fue dado de alta un par de dias después, volviendo a ser ingresado tan solo 5 días más tarde por orden judicial, ya que había realizado una agresión en el ámbito doméstico. El paciente admitió y aceptó los hechos, se encontraba calmado, lúcido y bien orientado, pero los médicos refieren que les costó entenderlo debido a problemas en el habla que podian dar lugar a una afasia mixta.

Tras el ingreso, se le realizó un estudio de coagulabilidad y por parte de Neurología y Hematología se le recomendó tomar anticoagulantes. Además, 
durante su estancia en el hospital, recibió tratamiento con Amisulpuiride $1200 \mathrm{mg}$. al día, Lorazepam $3 \mathrm{mg}$. al día, Clotiapina $40 \mathrm{mg}$. cada noche, Topiramato $200 \mathrm{mg}$. cada noche, Fragmin 10000 unidades, una toma cada 12 horas y su tratamiento habitual. Evolucionó favorablemente y le dieron el alta debido a la mejora que presentaba.

Años después, el paciente entró y salió del hospital puntualmente a pesar de tener varios ingresos más en la Unidad de agudos (psiquiatría), aunque únicamente debido a delirios auditivos típicos de la esquizofrenia paranoide, sin ningún episodio agresivo ya que se encontraba estable y controlado.

En abril de 2015 el paciente fue ingresado en el centro psiquiátrico Dr. Esquerdo en San Juan de Alicante por orden judicial tras el episodio de agresividad doméstica acaecido en 2010.

En la actualidad, sus habilidades básicas y fundamentales se encuentran conservadas siendo una persona autónoma. Presenta una limitación en el habla (disartria) por las secuelas del ictus. Sus habilidades sociales también se encuentran conservadas; tiene amigos y se relaciona bien, además es abierto, sociable y muy amable tanto con el personal sanitario como con sus compañeros y con nosotros mismos a la hora de realizar las entrevistas y las pruebas.

\subsection{ANÁLISIS Y DESCRIPCIÓN DE LAS CONDUCTAS LINGÜÍSTICAS PROBLEMÁTICAS}

En la primera entrevista pudimos comprobar con claridad el incremento de los síntomas psicofisiológicos de ansiedad: temblores, sudoración, tensión muscular y, como consecuencia de todo ello, un habla precipitada, llena de saltos y poco entendible. La segunda vez que nos reunimos con él, el paciente se encontraba más calmado; además, él mismo nos comentó que ese dia se encontraba mucho mejor (en el terreno lingüístico) y nos avisó de que le entenderíamos más y mejor, y así fue ${ }^{20}$.

Así pues, tras varias sesiones de observación, fuimos capaces de concluir que D. T. M. tiene problemas en la movilidad facial, mostrando rigidez en la región oro-lingual, según el estado en el que se encuentre (cansado, bajo de ánimos, nervioso...), muestra rasgos de disfemia, tartamudeando y entrecortando las palabras, trabándose y siendo incapaz de terminar las frases por verse impotente ante la situación debido a la rigidez y falta de movilidad que padece en la región facial antes mencionada. Durante la realización de las pruebas y los test nos dimos cuenta de que el paciente confunde $\mathrm{s}$, $\mathrm{t}$ y $\mathrm{r}$ en la escritura, que tiene problemas para pronunciar los fonemas $/ \mathrm{g} / \mathrm{g} / \mathrm{p} /$, $/ 1 /, / \mathrm{m} /, / \mathrm{ch} /, / \mathrm{n} /, / \mathrm{b} /, / \mathrm{s} /, / \mathrm{d} /, / \mathrm{r} /, / \mathrm{t} / \mathrm{y}$ que cambia vocales que le parecen complejas de pronunciar, por la vocal a: "escribar" por escribir, por ejemplo, ya que esta no tiene mucha dificultad de articulación.

\footnotetext{
${ }^{20}$ De hecho, aunque podamos decir que el lenguaje es una capacidad en la que, evidentemente, no existen emociones, el acto verbal, por el contrario, nunca puede actualizarse sin ellas (Van Lancker y Pachana, 1998: 310).
} 
Como hemos mencionando, las pruebas realizadas fueron extraídas del Programa Integrado de Exploración Neuropsicológica (PIEN), Test-Barcelona (Peña-Casanova, 1990), con objeto de valorar su expresión oral, comprensión oral, lectura y escritura. Elegimos este programa por su prestigio académico y precisión.

En las pruebas de expresión oral, valoramos el lenguaje espontáneo del paciente mediante conversaciones, narración temática y descripciones de láminas, puntuando la fluencia y el contenido informativo y la prosodia, además también de la orientación. Le realizamos pruebas de lenguaje automático y control mental, haciendo que completara unas series en orden directo y otras series en orden inverso también. Para las pruebas de comprensión verbal utilizamos unos test y unas láminas, pidiéndole al paciente que señalase las imágenes y le dimos unas órdenes (de más simples a más complejas) para ver cómo reaccionaba, además de realizarle exámenes de repetición verbal (sílabas, pares de sílabas, palabras pares de mínimos, palabras y frases también con distintos niveles de dificultad, repetición del error semántico y preguntas con material verbal complejo). Le realizamos las pruebas de comprensión porque debido a su condición mental, pensamos que esta estaría bastante afectada, y decidimos realizarle estas pruebas a pesar de no estar relacionadas con la disartria. Finalmente, en la exploración de la lectura y escritura, le realizamos unas pruebas de comprensión lectora sin verbalización (relación palabra-imagen, identificación y compresión de letras y ejecución de órdenes escritas, además de la identificación del objeto que completa que la frase) y con verbalización (letras, números, logatomos, palabras y un texto); y pruebas de mecánica de la escritura, con dictado de números, letras y frases, además de la valoración de la escritura espontánea en la que incluimos pruebas como la denominación escrita y la escritura narrativa.

A continuación, expondremos de manera más específica las pruebas que realizamos al paciente:

\subsubsection{PRUebas De EXPRESIÓN ORAL}

Como hemos dicho, aquí pretendemos valorar:

1. Primero, el lenguaje espontáneo mediante la aplicación de las siguientes pruebas:

A. La conversación o narración de datos básicos mediante preguntas como el nombre, la edad, el domicilio, la familia o la profesión. En esta prueba se evalúa la capacidad verbal, no la veracidad de las respuestas que da el paciente, ya que eso es parte de la prueba de orientación. La puntuación en esta prueba será 1 punto en cada respuesta bien dada y bonificaciones según haya sido el lenguaje fluente, pero con 
pérdida de información, o un uso normal del lenguaje con el contenido informativo completo hasta un máximo de 8 puntos.

B. La narración temática de un tema; por ejemplo, del bosque, haciendo referencia a distintos campos semánticos relacionados con el tema en cuestión. Esta narración puede dividirse en fragmentos o elementos de información. Si el paciente no se refiere a todos los aspectos que hemos fijado se le puede ayudar mediante preguntas. La puntuación en esta prueba será de 0 a 6 puntos siendo el 0 una no comunicación por reducción y el 6 un uso normal del lenguaje, con información completa de todos los aspectos solicitados.

C. La descripción de una lámina presente en las fichas del test para que se haga referencia a elementos semánticos parciales de la imagen. Si el paciente no colabora se le puede animar para que conteste con respuestas elaboradas. La puntuación de esta prueba se corresponde con la anterior, en una escala del 0 al 6, para evaluar el uso que hace del lenguaje el paciente, entre el fluente tipo afásico o no afásico, el no fluente o el normal.

En estas pruebas valoramos la capacidad verbal en distintas situaciones y el contenido de la información. Asimismo, nos ayudamos de grabaciones que nos permitan valorar de manera adecuada el uso que hace de su capacidad de lenguaje durante unos 5 minutos aproximadamente.

2. En segundo lugar, valoramos la prosodia con una prueba ligada a la anterior, para saber el ritmo y la melodía que posee el paciente; esto es, la capacidad que tiene el paciente de modificar la melodía durante la comunicación y el ritmo. La puntuación de esta prueba se evalúa de 0 a 3 puntos en los dos aspectos siendo el 0 una ausencia del aspecto que se esté tratando y el 3 un caso de prosodia normal.

3. En tercer lugar, la orientación, que se evalúa en tres apartados:

A. Orientación en persona, respondiendo a preguntas sobre sí mismo, como su nombre, edad, dónde y cuándo ha nacido, familiares, dirección y profesión. Esta prueba tendrá un máximo de 7 puntos dando por cada respuesta bien dada un punto.

B. Orientación en lugar, respondiendo, entre otras, a preguntas sobre el lugar donde se le hace la intervención, dónde vive o el nombre del establecimiento en el que se encuentra. El paciente tiene que responder a 5 preguntas que corresponden a los cinco puntos máximos que se pueden sacar en esta prueba, uno por cada respuesta bien dada.

C. Orientación en tiempo: respondiendo a cuestiones sobre el día de la semana en el que está, el mes, el año, la hora, etc. La puntuación de esta prueba puede ser un máximo de 23 puntos repartidos en seis puntos sobre los que se pregunta. 
4. En cuarto lugar, valoramos el lenguaje automático-control mental mediante una prueba que consiste en evaluar la capacidad de decir en orden directo e inverso la serie del 1 al 20, los dias de la semana y los meses del año. En esta prueba usamos una grabadora para mantener las respuestas posteriormente. Cada vez que terminamos la prueba anotamos el tiempo empleado por el paciente para hacerlo. La puntuación sin tiempo es hasta 3 puntos y la puntuación con tiempo varía si es orden directo o inverso. En el orden directo hay un máximo de 6 puntos y no se pueden superar los 8 segundos y, en el orden inverso también hay un máximo de seis puntos, pero el tiempo llega a 15 segundos.

\subsubsection{PRUEBAS DE COMPRENSIÓN ORAL}

En el caso ahora de la evaluación de la compresión oral, pretendemos valorar:

1. Primero, la repetición verbal, mediante un test que se compone de seis apartados: repetición de 8 sílabas, repetición de 8 pares de sílabas, repetición de 8 logatomos, repetición de 8 pares de palabras (pares mínimos), repetición de 10 palabras y repetición de 9 frases que hacen un total de 60 palabras. En esta prueba el examinador tiene que tapar su boca para evitar que el paciente lea sus labios, sobre todo en las sílabas y también es importante el uso de la grabadora. La puntuación consiste en dar 1 punto por cada elemento correctamente repetido, pero quitar también 1 punto si el paciente añade alguna palabra de más a lo que se le ha dicho o por la alteración del orden de las palabras. La puntuación máxima que se puede alcanzar en cada apartado es de 8 puntos en sílabas, pares de sílabas, logatomos y pares de palabras (pares minimos); 10 puntos en las palabras y 60 en las frases.

2. Segundo, la repetición de error semántico, mediante la repetición de 10 frases con errores semánticos. Este test se hace para puntuar los cambios que hace el paciente sobre las frases (si se da cuenta y la conducta que presenta antes dichos errores). No se debe permitir que el paciente haga chistes o comentarios, por eso hay que decirle que tiene que continuar con el ejercicio. La puntuación oscila entre 0 y 4 puntos, siendo 0 cuando el paciente se niega a repetir y hace comentarios de todo, y 4, cuando el paciente hace una repetición normal de lo que se le dice.

La leche es negra

Los aviones van por el mar

El azúcar es salado

3. Tercero, la comprensión verbal, mediante la realización de las pruebas consistentes en: 
A. Señalar imágenes. En esta prueba el paciente deberá señalar en una lámina lo que se le pide después de la explicación del ejercicio. La puntuación varía según el tiempo utilizado que son 30 segundos como máximo por elemento. La parte directa es 1 punto cada respuesta correcta siendo como máximo 12 puntos, y la parte con tiempo tiene como máximo 36 puntos que varian según los segundos que tarda el paciente en contestar o señalar cada dibujo, a partir de los primeros 5 segundos.

B. Señalar partes del cuerpo. Ahora el paciente debe señalar las partes del cuerpo que se le dicen en su propio cuerpo. Hay que tener en cuenta la respuesta y el tiempo empleado, que tiene como máximo 30 segundos por parte. La puntuación directa es 1 punto cada acierto teniendo como máximo 6 puntos, y la puntuación con tiempo tiene las mismas pautas que en el apartado de señalar imágenes, teniendo como máximo 18 puntos.

C. Comprensión/realización de órdenes verbales. En esta prueba se dan unas órdenes al paciente que tiene que hacer y se tiene en cuenta lo que hace y en cuanto tiempo lo realiza con un máximo de 30 segundos por orden. La puntuación es 1 punto por cada acción bien realizada hasta llegar a 16 puntos como máximo.

D. Material verbal complejo. Finalmente, esta prueba consiste en contestar si o no a las preguntas que se realizan para tener en cuenta el tiempo que tarda en responder teniendo 30 segundos como máximo. La puntuación directa es 1 punto por cada respuesta correcta hasta un máximo de 9 , y la puntuación con tiempo varía según el intervalo de segundos empleados, si está en 5 segundos se le da 3 puntos, entre 5 y 10 segundos, dos puntos, entre 10 y 30 segundos, un punto, o más de 30 segundos, ningún punto, hasta llegar a un máximo de 27 puntos.

\subsubsection{PRUEbas DE LeCTURA y ESCRITURA}

Finalmente, en el caso ahora de la lectura y escritura, pretendemos evaluar su comprensión mediante una serie de pruebas.

1. En el caso de la lectura las pruebas fueron las siguientes:

A. Apareamiento de la palabra/imagen. Con la utilización de láminas se trata de emparejar cada objeto con su palabra en un máximo de 20 segundos por palabra.

B. Discriminación de 6 letras. Se trata, en este caso, de realizar tres sonidos por lámina y comprobar el tiempo que tarda el paciente en asociarlo a la letra y si lo hace de forma correcta. El tiempo que tiene por letra es de 20 segundos. 
C. Discriminación de 6 palabras. Consiste en asociar la palabra que se dice con la que tiene escrita en la lámina con un máximo de 20 segundos por palabra.

D. Discriminación de 6 logatomos. Se trata de asociar el logatomo que se dice con el que tiene escrito en la lámina hasta un máximo de 20 segundos por logatomo.

La puntuación para estos cuatro apartados es directa y con tiempo. Directa es 1 punto cada acierto hasta un máximo de 6 , y la puntuación con tiempo depende de los segundos que se tarde en responder llegando hasta 18 puntos.

2. En el caso ahora de la evaluación de la escritura las pruebas fueron:

A. Comprensión/realización de 5 órdenes escritas. Esta prueba consiste en que el paciente va a leer ciertas órdenes en silencio y tiene que ejecutarlas teniendo un máximo de 20 segundos por orden. No se puntúa el tiempo, sino cómo se comporta el paciente desde que lee hasta que ejecuta y cómo la ejecuta. La puntuación llega hasta 12 puntos teniendo cada orden un punto.

B. Completamiento de frases y textos. Se trata de enseñar al paciente una serie de frases a las que le falta la última palabra, que tiene que completar. El tiempo máximo que tiene por frase es entre 20 y 30 segundos y se empieza a contar desde que el paciente empieza a leer en voz baja. La puntuación directa es 1 punto por cada respuesta correcta hasta llegar a un máximo de 8 puntos, y la puntuación con tiempo es la siguiente, con un máximo de 24 puntos:

Frases 1 a 5: 3 puntos $=0-5$ seg.; 2 puntos $=5-10$ seg.; 1 punto $=10-20$ seg.

Frases 6 a $8: 3$ puntos $=0-10$ seg.; 2 puntos $=10-20$ seg.; 1 punto $=20-30$ seg.

\section{Resultados}

A continuación, precisaremos los resultados que obtuvimos tras la realización de cada una de las pruebas.

\subsection{EXPRESIÓN ORAL}

Con las pruebas de expresión oral pretendiamos medir la capacidad comunicativa de nuestro paciente. En primer lugar, y para romper el hielo con el paciente, se llevó a cabo el primer subtest del 'Test Barcelona'. Dicho test consiste en valorar el lenguaje espontáneo del paciente con preguntas comunes a su día a día. En este test, nuestro paciente casi obtuvo la máxima puntuación.

A continuación, seguimos valoramos el lenguaje espontáneo del paciente mediante pruebas de conversación (en las que el paciente obtuvo seis puntos sobre ocho), narración temática (en las que obtuvo una puntuación de cuatro 
sobre seis) y descripciones de láminas (en las que el paciente obtuvo cuatro puntos sobre seis). En el gráfico siguiente podemos observar las puntuaciones:

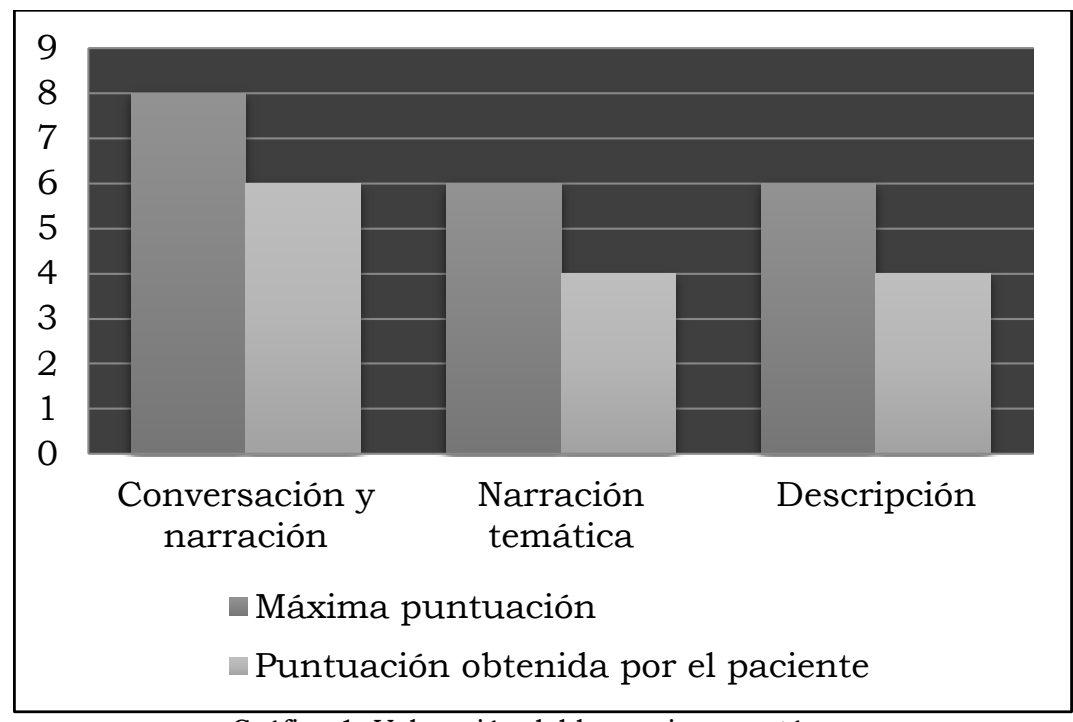

Gráfica 1: Valoración del lenguaje espontáneo

De los datos obtenidos podemos observar que, en el caso de la narración temática, no presenta un lenguaje afásico, pero sí ejecuta un uso muy pobre del lenguaje (más aún, teniendo en cuenta que se trata de un adulto), y con poca fluencia, costándole la articulación de las palabras y hasta teniendo que repetirlas en ocasiones por ser incapaz de finalizarlas. Por el contrario, el contenido de la comunicación no presenta ningún problema, a no ser la pobreza expresiva que ya hemos mencionado. En la descripción de la lámina, el paciente consigue cuatro puntos. Se intuye, por tanto, una pérdida de información discreta, aunque esta puede estar ligada a la esquizofrenia que padece. Casi todos los apartados son descritos de manera pobre, con una verbalización reducida sin llegar a ser afásica, siendo su vocabulario pobre en contenidos. Su habla varia, pero nunca llega a ser del todo fluente, trabándose y tartamudeando en situaciones de estrés. También constatamos una anomia discreta.

En segundo lugar, valoramos la prosodia con una prueba ligada a la anterior, para saber el ritmo y la melodía que posee el paciente. En la prueba de 'Ritmo', el paciente obtuvo una puntuación de un punto sobre tres, como se puede ver en el eje número uno de la gráfica 2. En la prueba de la 'Melodia', el paciente obtuvo una puntuación de un punto sobre tres también. 


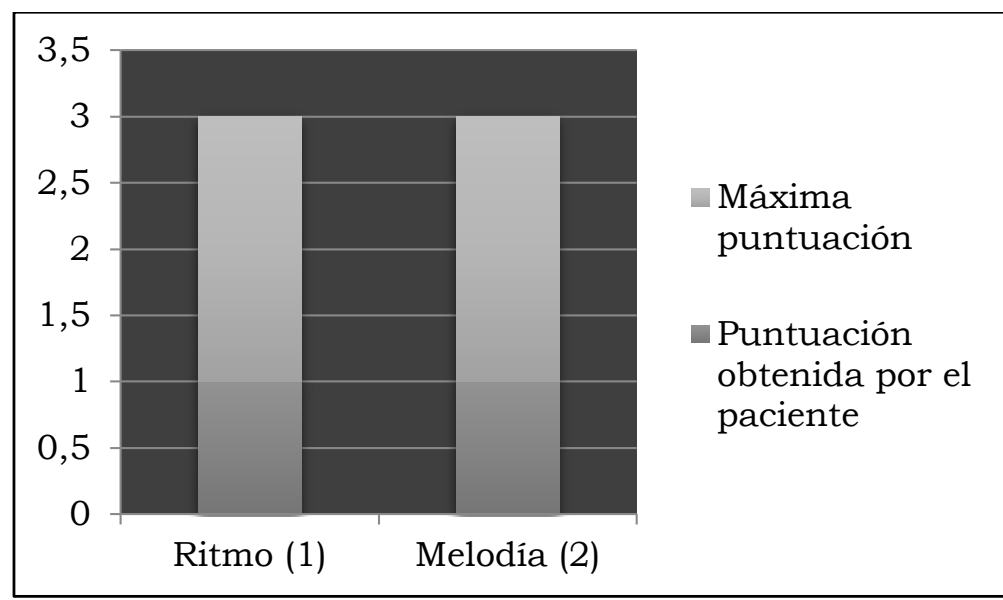

Gráfica 2: Valoración de la prosodia

El paciente comienza las conversaciones con interés y dispuesto a expresarse, pero al ver que se traba y que no articula adecuadamente lo que desea, comienza a tartamudear, utiliza pausas largas y busca sinónimos más simples y sencillos de pronunciar. Su melodía es monótona y plana, sin cambios y acompañada de un tono de voz muy bajo.

En tercer lugar, valoramos la orientación. Como ya mencionamos anteriormente, el paciente tiene un buen concepto sobre su mundo; conoce información sobre su persona, lugar y sobre el tiempo presente (día, mes, hora, etc.). El paciente obtuvo la puntuación máxima en ambas pruebas, tal como podemos observar en las gráficas.

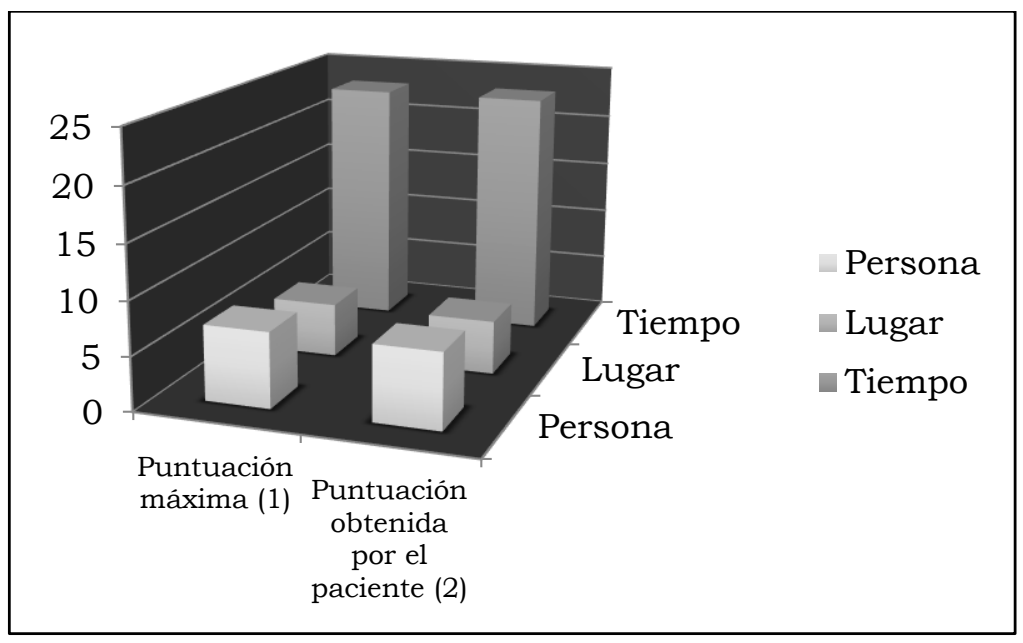

Gráfica 3: Valoración de la orientación. 
En ellas, podemos observar el eje número uno, que representa las puntuaciones totales, y a su lado, el eje número dos, que representa las puntuaciones del paciente.

Finalmente, para terminar con este apartado, precisaremos los resultados de la prueba de lenguaje automático y control mental. En esta prueba evaluamos la capacidad de decir en orden directo e inverso la serie del 1 al 20 , los días de la semana y los meses del año con control de tiempo y sin tiempo. En las series de orden directo, el paciente consiguió una puntuación (con tiempo) de tres puntos sobre seis; y una puntuación (sin tiempo) de tres sobre tres. En las series inversas, el paciente obtuvo una puntuación (con tiempo) de uno sobre seis; y una puntuación ( $\sin$ tiempo) de tres puntos sobre tres.

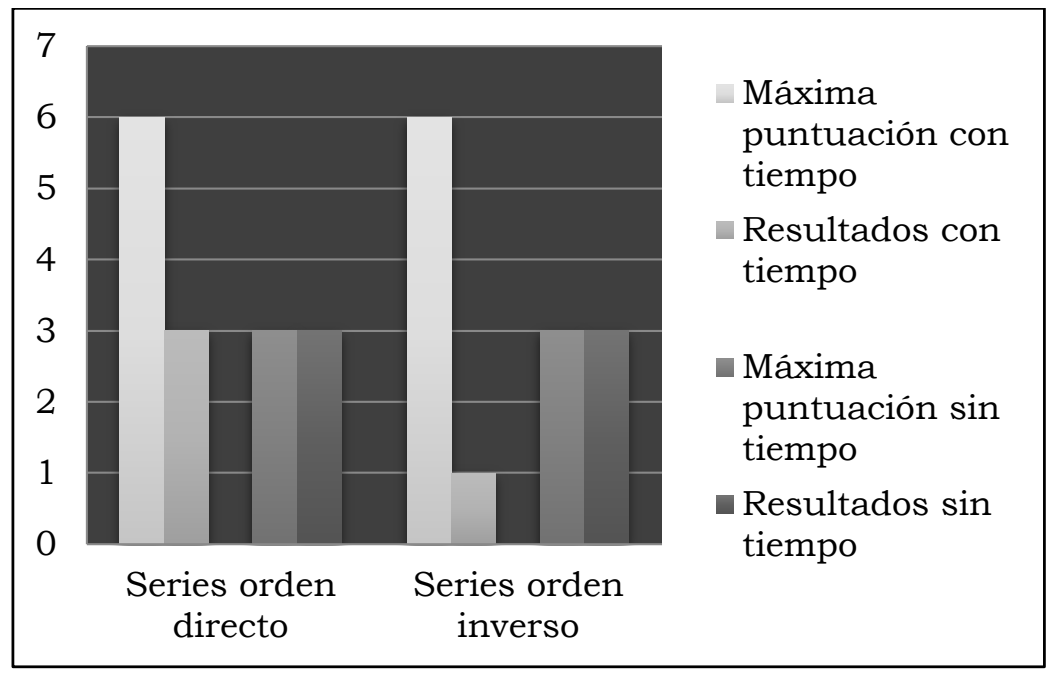

Gráfica 4: Valoración del lenguaje automático y control mental

Como puede apreciarse, el paciente no muestra ningún tipo de problema cuando la enunciación que se le pide no implica tiempo (sin importar el orden, directo o inverso); en cambio, cuando el tiempo se tiene en cuenta, el paciente no es capaz de cumplir con las expectativas, igualando o aproximándose a la puntuación que obtiene sin tiempo límite. Podemos observar, de esta manera, que los resultados del paciente descienden siempre que se le ponga un límite de tiempo, ya que debido a su problema articulatorio y la lentitud que este le produce, el residente no es capaz de cumplir con el objetivo propuesto.

\subsection{COMPRENSIÓN ORAL}

En el caso ahora de la evaluación de la compresión oral, valoramos, en primer lugar, la repetición verbal. En la gráfica 5 podemos observar las distintas puntuaciones que consiguió el paciente. En la prueba de 'sílabas', 
'Pares de sílabas', 'Logatomos', 'Palabras pares mínimos' y 'Palabras', el paciente consiguió unas puntuaciones muy bajas, siendo en ocasiones no superiores a tres de ocho. Además, en la prueba de 'Frases', solamente obtuvo trece puntos sobre sesenta.

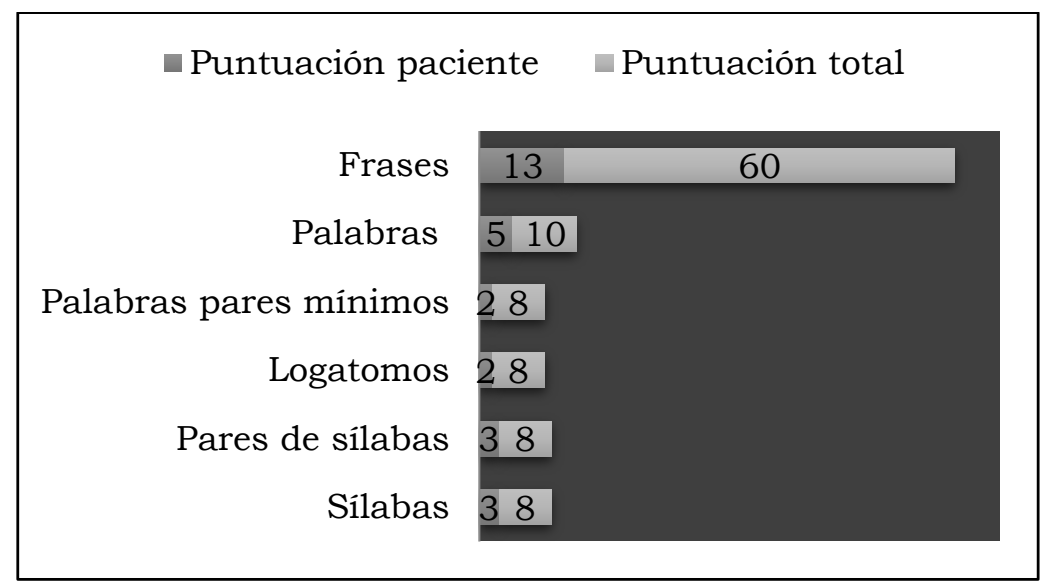

Gráfica 5: Valoración de la repetición verbal

En estos test se le pidió al paciente que repitiese distintos vocablos y palabras, mostrando distorsión en las palabras, fonemas, orden y pronunciación, resultando en algunas ocasiones, casi ininteligible. Cuando se le pidió repetir las frases completas más largas, el paciente no conseguía llegar a la mitad de la palabra. Repetía las palabras con intención de rehacer las frases correctamente, pero además de alterar el orden tras varios intentos, no lo conseguía y se frustraba. Esto nos lleva a la conclusión de que el paciente comprende lo que se le dice, pero tiene graves problemas para reproducirlo.

En segundo lugar, valoramos la repetición de error semántico, mediante una prueba que consistía en repetir 10 frases con errores semánticos comprobando si se daba cuenta de los errores y la conducta que presenta antes dichos errores. Aquí, el paciente mostró las mismas dificultades que en el test anterior al repetir frases que contenían errores e incongruencias, pero no por las incongruencias que contenían sino por su problema articulatorio. 


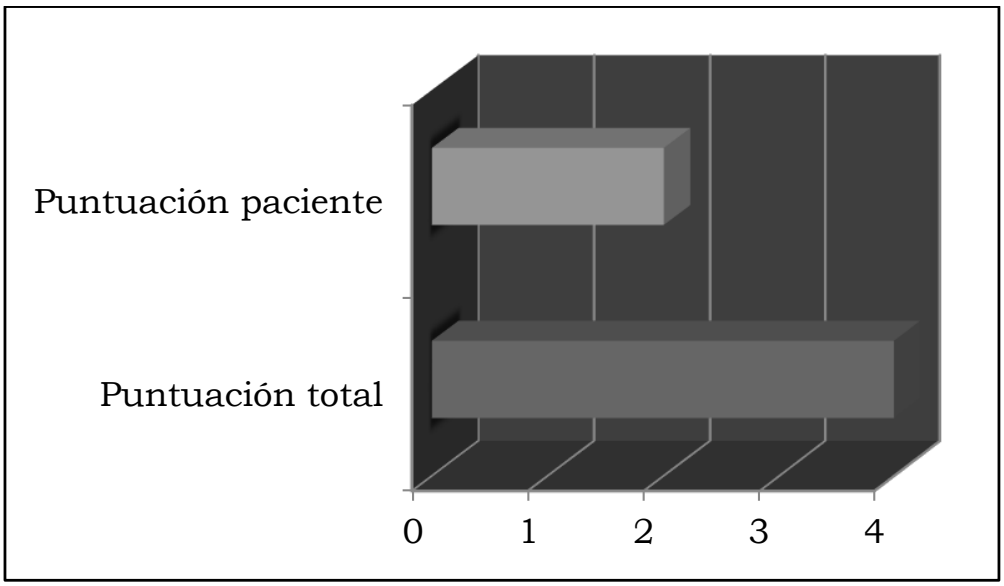

Gráfica 6: Valoración de la repetición de errores semánticos

La puntuación total para conseguir en esta prueba era de cuatro puntos, de los que el paciente consiguió dos.

Finalizando con los test de esta categoría, realizamos, en tercer lugar, el test de comprensión verbal en el que al paciente se le fueron dando una serie de fichas en las que tenía que señalar la orden que se le daba. Estas pruebas también fueron evaluadas siguiendo los criterios con tiempo y sin tiempo. En las cuatro partes del test consiguió la mayor puntuación, habiendo señalado las respuestas correctas y dentro del tiempo mínimo.

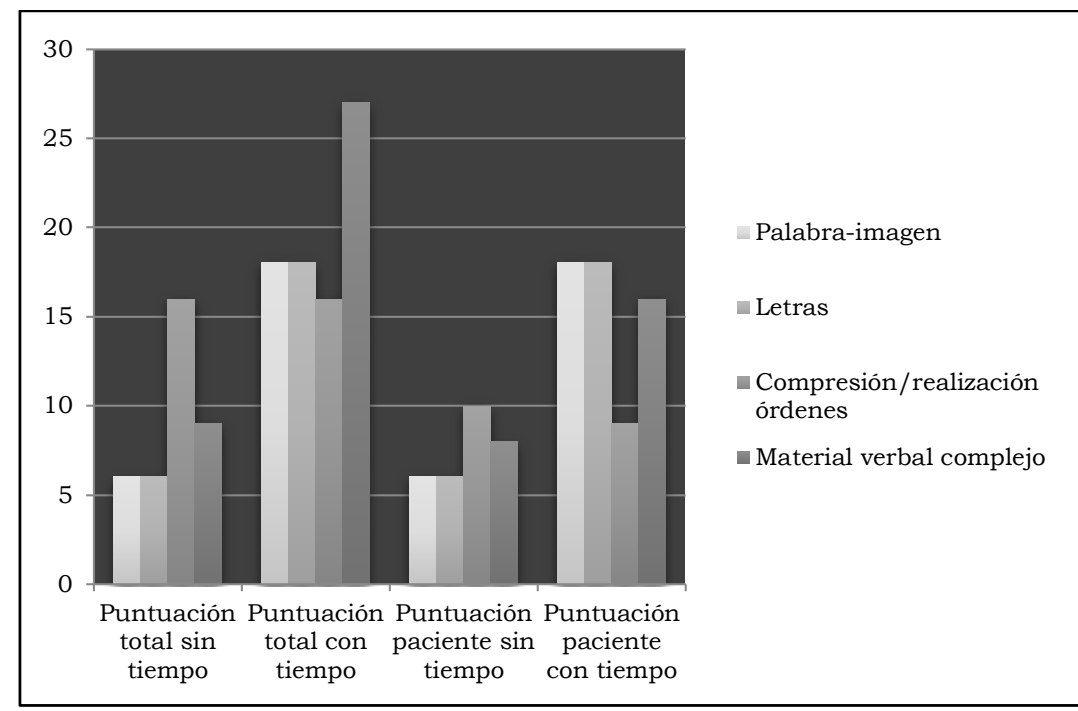

Gráfica 7: Valoración de la comprensión verbal

Los datos nos dan a conocer que el paciente no tiene ningún impedimento en la comprensión, no siendo así en la producción, ya que como podemos 
observar no existen problemas en las ocasiones en las que no tiene que hablar. Las órdenes las realizó con problemas, debido a un procesamiento algo más lento de lo habitual debido a la esquizofrenia.

\subsection{LECTURA Y ESCRITURA}

Finalmente, en el caso ahora de la evaluación de la lectura y escritura, los resultados fueron obtenidos mediante la realización de las pruebas (las más pesadas, quizá, para el paciente) que señalamos a continuación.

Para evaluar la comprensión lectora le pasamos una serie de fichas para que relacionase palabras con objetos, encontrase en las fichas una palabra dada de forma oral, distinguiese los fonemas asociándolos a la letra correspondiente, etc. En cada uno de los ejes de las gráficas se puede discernir los diferentes datos que consiguió el paciente.

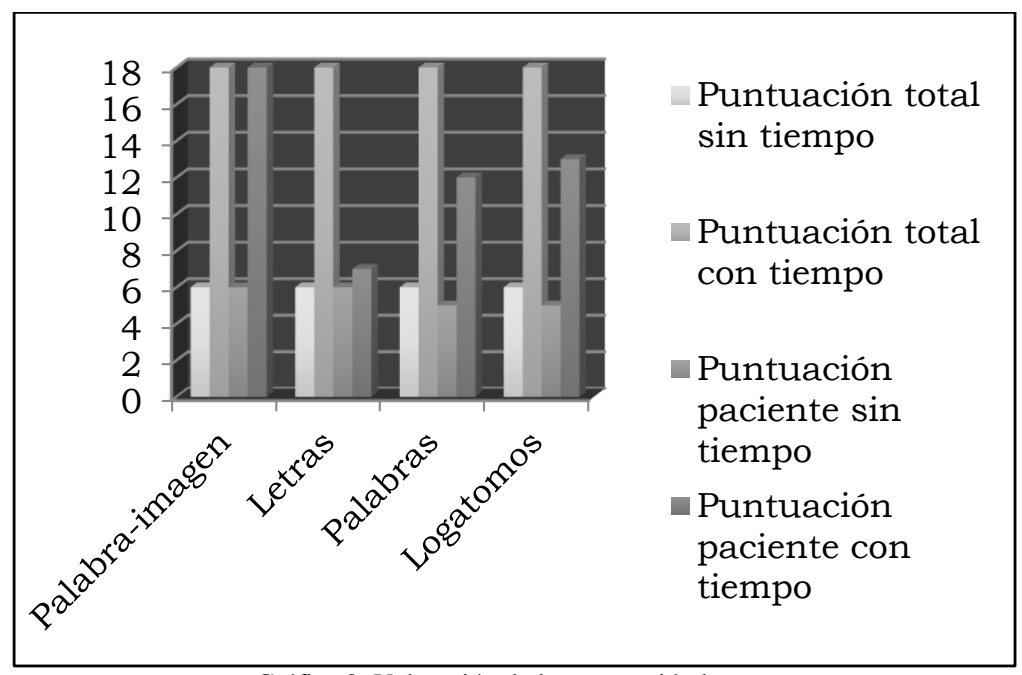

Gráfica 8: Valoración de la compresión lectora

La parte en la que más fallos tuvo fue en la de 'Letras' (con tiempo); aquí se aprecia un ligero descenso con respecto a los demás resultados. El mayor problema lo muestra cuando la lectura va acompañada de verbalización, lo que, una vez más, nos demuestra que el paciente no tiene ningún tipo de problema en entender lo que lee o se le dice, sino que el problema se encuentra a la hora de expresarlo verbalmente.

Finalmente, para evaluar comprensión escrita, se le paso un ejercicio de frases $y$ textos. En él, el paciente entiende a la perfección las órdenes escritas y después las lleva a cabo con regularidad. Aunque sí es notable un ligero retraso en el procesamiento mental de estas órdenes debido, sobre todo, a la lentitud que le produce la esquizofrenia. En este apartado, se tuvo que leer unas frases incompletas y se daban cuatro opciones para elegir la correcta. Debido al ligero retraso en el procesamiento de la información por 
parte del paciente, este tardó un poco, aunque lo consiguió hacer todo dentro del tiempo máximo permitido. Aquí podemos observar los resultados:

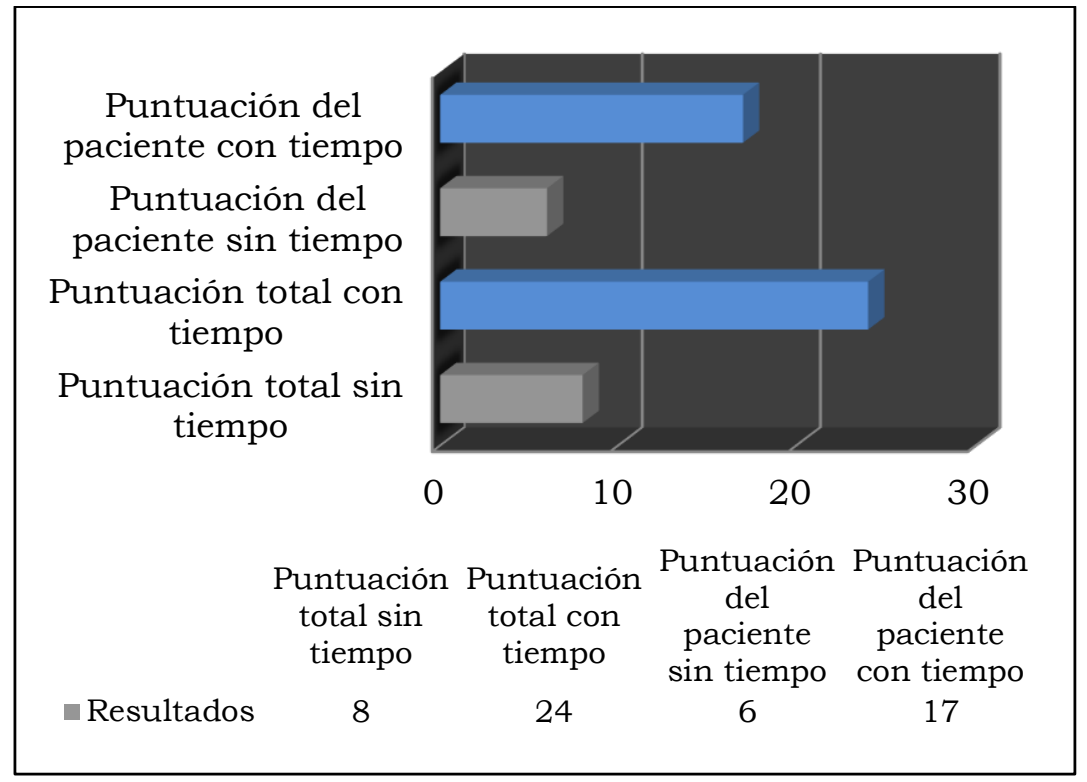

Gráfica 9: Valoración de frases y textos

Como puede apreciarse, la parte más dificil para el paciente fue sin duda la de la escritura. Esto tiene que ver más con la esquizofrenia y el desorden mental que esta le produce que con la disartria. Aquí el paciente pudo realizar correctamente las pruebas más sencillas como copia y actos mecánicos (su nombre y dirección), siéndole imposible la prueba de escritura narrativa, dado que no era capaz de formar más de 4 palabras, las cuales le costaba repetir. Uno de los aspectos que más curiosidad nos suscitó del paciente fue la necesidad de repetir en voz alta las palabras que deseaba escribir. Como la mayoría no era capaz de pronunciarlas, podemos llegar a la conclusión de que, al no poder oírlas correctamente, se mostraba incapaz de escribirlas, ya que en el dictado que le realizamos, no mostró ese problema.

Como los resultados nos han permitido observar, el paciente padece muchos más problemas a la hora de comunicarse que en cualquier otra interacción. Le realizamos unas pruebas de comprensión que, a pesar de no ser necesarias en un caso de disartria, sí que lo eran debido a la esquizofrenia que padece, ya que esta le produce un desorden en el pensamiento que, de hecho, se ve reflejado en los resultados. Con todo ello, hemos podido dilucidar que el retraso que padece a la hora de procesar las órdenes, viene dado por su condición mental, aunque no representa un gran problema, ya que el paciente puede desenvolverse con total normalidad, menos a la hora de expresarse. 
En los test y las pruebas monitorizadas el paciente se desenvuelve mejor que en el nivel conversacional (de manera espontánea y sin ser consciente de que está siendo observado), ya que, al saber que está siendo juzgado, en cierto modo, intenta esforzarse mucho más que en cualquier otra situación diaria. Este hecho ha posibilitado que el paciente se ponga nervioso con mayor facilidad. Además, hemos podido ver cómo la escritura es el punto más débil del residente, ya que no fue capaz de escribir más de cuatro palabras seguidas. Mientras realizábamos el ejercicio, D. T. M. intentaba verbalizar lo que pensaba para así poder ordenarlo coherentemente y escribirlo, pero al tener dificultades en la verbalización, la escritura se le hizo prácticamente imposible.

\section{Propuesta de intervención}

Tras los datos obtenidos, presentamos ahora un plan de rehabilitación que pueda ayudar al paciente a mejorar sus habilidades comunicativas, propiciando también la mejoria de su disartria.

En este sentido, a partir de la consideración de los rasgos lingüísticos problemáticos que presenta el paciente, proponemos un plan de rehabilitación para que le pueda ser aplicado por un terapeuta/logopeda, siguiendo las propuestas de León-Carrión, Viñals, Vega y Dominguez-Morales (2001: 39 y ss.).

Este plan consistiría en la combinación de diversos ejercicios basados en la rehabilitación de los cinco procesos motores básicos (respiración, fonación, resonancia, articulación y prosodia), basándonos en las propuestas de intervención de Melle (2008) y en el manual de logopedia de Peña-Casanova (2001).

1. La respiración es un aspecto que puede dificultar tanto el habla como el tono, ritmo, entonación, etc. Para trabajarla, proponemos ejercicios de hinchar globos o controlar la respiración de manera abdominal, por medio de la relajación. También hacer juegos con pompas de jabón sería un ejercicio útil, aunque tal vez más dirigido a edades inferiores.

2. Para la fonación, se entrenaría en la emisión de fonemas empleando balbuceos, imitando sonidos de animales, vocales, etc. Para ello, debe trabajarse también la articulación precisando la posición adecuada de los músculos para emitir un sonido determinado. Para lograrlo se harian ejercicios de movilización de los labios, la lengua y la mandíbula, así como la combinación de todos los movimientos para que el paciente llegase a ser capaz de articular sonidos concretos.

3. Para la resonancia habria que trabajar con los órganos fonadores, haciendo hincapié en la articulación, de la misma manera que se explica en el punto anterior.

4. También proponemos ejercicios logopédicos que le permita aprender a mover la boca correctamente, siendo capaz de ser entendido a la hora de 
articular las palabras, estimulando los músculos que intervienen en el proceso del habla (entrenando la coordinación, la fuerza y la agilidad, por ejemplo, mediante la repetición verbal de sílabas, pares de sílabas, palabras aisladas y finalmente frases; esforzándose en controlar la saliva, los movimientos involuntarios y la masticación). Hinchar globos de distintos tamaños o mascar chicle podrian ayudarle a controlar y mejorar los movimientos de la región afectada, la oro-lingual.

5. La relajación es fundamental a la hora de conseguir seguridad y facilitar la entonación y la pronunciación, por lo que el logopeda debería centrarse también en enseñarle unas técnicas de relajación. La práctica de actividades relajantes como el yoga o el esfuerzo por controlar la respiración con movimientos en el vientre focalizando su concentración en el mismo podrían serle de ayuda también a la hora de relajarse. Además, en estos casos, el refuerzo positivo por parte de los referentes (maestros, logopedas, terapeutas...) resulta crucial para lograr que el paciente se sienta a gusto y realizado, y, por tanto, más tranquilo. Es muy importante también que el paciente siga controlado con su medicación y que esta sea la adecuada ya que las fluctuaciones no son nada positivas y le impiden la relajación y el autocontrol.

6. Finalmente, la discriminación auditiva es una parte esencial que debe entrenar el paciente, ya que, si tiene problemas para reconocer los sonidos, no podrá repetirlos con exactitud. Este problema le ocurre con mucha frecuencia al paciente, ya que, como hemos mencionado anteriormente, muestra dificultades a la hora de escribir lo que no puede pronunciar. Algunas actividades para mejorar la discriminación auditiva serian las pruebas de dictado (con distintos niveles de dificultad, comenzando por grafias, pasando por las silabas, los pares de sílabas, los logatomos, las palabras, y, finalmente, la formación de frases), todo ello con su posterior verbalización.

Como es posible observar, todos los procesos se necesitan entre sí, siendo todos ellos de gran relevancia, necesidad e importancia para posibilitar la rehabilitación del paciente con disartria.

\section{Conclusiones}

Tras el análisis del caso, el trabajo con el paciente y el proceso de investigación realizado, hemos llegado a una serie de conclusiones que consideramos relevantes para entender la tarea realizada. Las expondremos ahora de manera somera.

Como manifestamos al principio del trabajo, nos planteamos una serie de problemáticas o preguntas que iban a gestionar nuestra investigación. Tras la tarea realizada podemos sintetizar las respuestas que hemos obtenido. 
Confirmamos que la disartria es un trastorno de la programación motora del habla, que viene dada por una lesión cerebral y que se distingue de la afasia motora debido a que no es un trastorno del lenguaje, sino del habla, y con ello de la articulación de los fonemas ${ }^{21}$. Entre sus sintomas más frecuentes podemos apreciar los cambios en el timbre de la voz, siendo esta generalmente muy baja y con poca fuerza, el "arrastre" de las palabras, el habla escandida, es decir, a 'saltos' y con interrupciones, la lentitud en el habla, la movilidad limitada de la lengua, los labios y la mandíbula, la entonación y el ritmo anormales al hablar, la ronquera, la voz entrecortada y el babeo o escaso control de la saliva. Hay diversos tipos de disartria y se clasifican según la zona del encéfalo que se encuentre afectada por la lesión, sus sintomas (características sintomatológicas) y la toma articulatoria.

La esquizofrenia, por otro lado, es un trastorno mental grave que se caracteriza por una distorsión del pensamiento, las percepciones, las emociones, el lenguaje, la conciencia de sí mismo y la conducta. El hecho de oír voces y los delirios son algunas de las conductas más habituales. Este tipo de paciente suele perder el control con facilidad y suele ser propenso a comportarse de manera agresiva, llegando incluso a agredir a sus más allegados si la situación les pone en esa tesitura. La gran mayoría de estas alucinaciones vienen en forma de advertencia o petición por parte de seres fantásticos, padeciendo además delirios místicos. La esquizofrenia es tratable, siendo eficaces la farmacoterapia y el apoyo psicosocial, pero sin llegar a existir una cura total. La manera de hablar de una persona suele darnos indicios significativos sobre un trastorno del pensamiento. La esquizofrenia trae consigo alteraciones en el lenguaje, aunque podemos ver que, normalmente, los pacientes esquizofrénicos que se encuentran en tratamiento, suelen presentar también problemas en el habla.

Estas dos patologías comparten muchas de las disfunciones en el habla, como el uso del tono bajo, la ausencia de ritmo, lentitud, alteración en la articulación de las palabras, falta de fuerza, debilidad, falta de coordinación, etc. Sin embargo, también existen varias diferencias entre ellas; a saber,

- La disartria es un trastorno lingüístico que afecta únicamente al habla, mientras que la esquizofrenia presenta principalmente problemas en el lenguaje, aunque sin excluir los del habla.

- La intensidad con la que aparecen los sintomas en el habla que comparten ambas patologías es distinta. En la disartria los déficits lingüísticos se encuentran mucho más agravados que en el caso de la esquizofrenia.

\footnotetext{
${ }^{21}$ La distinción fundamental, por tanto, entre Trastorno de habla y Trastorno del lenguaje queda definida según Barrueco et alii (1990: 152) en que el trastorno del habla se localiza no en la organización del lenguaje sino en las praxias verbales, en la alteración de los procesos que controlan la producción verbal. Es decir, los errores que parecen en los trastornos del habla y que implican un componente sintáctico, no se deben a un déficit en su programación cognitiva, sino a un problema en los movimientos articulatorios para producir el enunciado; esto es, en las praxias articulatorias.
} 
- La articulación de un paciente disártrico está más afectada que la de un paciente esquizofrénico, llegando a tener bastantes problemas en la producción de muchos fonemas.

- El habla de un paciente esquizofrénico es monótona, sin énfasis, ni cambios en el tono de voz y en el volumen. En el caso del paciente disártrico, también es monótona y plana, pero existe una mayor lentitud en la producción de sonidos, presentando un habla entrecortada.

- En ciertos casos, la rigidez en la región oro-lingual de las personas con disartria es apreciable, no siendo así en la esquizofrenia.

- La voz del paciente disártrico suele ser tensa, nasal y áspera, no así en el esquizofrénico.

- La disartria viene dada como causa secundaria a una lesión cerebral, siendo el habla la que se ve afectada de manera principal, mientras que la esquizofrenia consiste en la perturbación del curso del pensamiento y los problemas que provoca en el habla son secundarios a la patología.

- Muchas de las alteraciones en el habla de un paciente con esquizofrenia podrían deberse, incluso, al uso de neurolépticos y antipsicóticos.

Estudiamos el caso clínico de un paciente con esquizofrenia paranoide y disartria aplicando para la valoración de su expresión oral, comprensión oral, lectura y escritura las pruebas extraídas del Programa Integrado de Exploración Neuropsicológica (PIEN), Test-Barcelona (Peña-Casanova, 1990).

Con los resultados obtenidos del estudio de su expresión oral, llegamos a la conclusión de que el mayor problema que presenta el paciente se encuentra en la articulación, debido a las alteraciones en la de movilidad facial y a la rigidez en la región oro-lingual. Por ello, su articulación es muy lenta, confusa y en ocasiones imposibilita la intelección del discurso. Presenta, además, problemas en la articulación de los fonemas $/ \mathrm{g} /, / \mathrm{p} /, / 1 /, / \mathrm{m} /$, $/ \mathrm{ch} /, / \mathrm{n} /, / \mathrm{b} /, / \mathrm{s} /, / \mathrm{d} /, / \mathrm{r} /, / \mathrm{t} /$. Cambia también vocales que le parecen complejas de pronunciar, por la vocal /a/. Sin presentar un lenguaje afásico, hace un uso muy pobre de su capacidad lingüistica, con baja fluencia y disfemia en situaciones de estrés, que le lleva a entrecortar palabras, trabarse y a dejar frases incompletas. La pronunciación está muy afectada debido a la disartria. Hay pérdida discreta de información, presenta un vocabulario pobre y algunos casos de anomias. Consecuentemente, su melodía es monótona y plana, acompañada de un tono de voz muy bajo.

Por otro lado, su comprensión está bastante preservada, mostrando solo algunos casos de procesamiento más lento de la información y retraso en el cumplimiento de las órdenes, debido, sobre todo, a las consecuencias de la esquizofrenia que padece.

La escritura y la lectura están afectadas, mostrando más problemas para expresar sus ideas de manera escrita que para entender lo que se le dice o lo que lee. Confunde las grafias s, t y r. Nos encontramos, pues, frente a un 
procesamiento lento de la información, que imposibilita al paciente la escritura narrativa, siendo incapaz de escribir más de 4 palabras.

Para paliar estas deficiencias proponemos un plan de intervención que debe ejecutarse por rehabilitadores/logopedas/terapeutas para que el paciente pueda ser capaz de rehabilitarse poco a poco. Los ejercicios que lo integran se basan en la rehabilitación de los cinco procesos motores básicos; esto es, la respiración, la fonación, la resonancia, la articulación y la prosodia. Las pruebas que proponemos irian enfocadas al control de estos cinco procesos motores.

En este proceso el lingüista clínico es una pieza clave, junto a un equipo multidisciplinar integrado por médicos especialistas, psicólogos y logopedas. El médico sería el encargado de descartar el problema físico o físiológico en los órganos productores del habla, después el paciente pasaría a ser evaluado por el psicólogo que descartaría las posibles causas psicológicas de ese problema en el habla, siendo evaluado, a continuación, por el lingüista clínico, que se encargaría de estudiar los déficits comunicativos, reconociendo (junto al resto del equipo) el foco del problema y creando el plan de intervención adecuado a las necesidades del paciente para que, finalmente, el logopeda/rehabilitador/terapeuta, lo aplicase 22 .

Tras el estudio del caso, hemos podido observar la utilidad y necesidad del lingüista clínico, ya que hay personas diagnosticadas de alguna patología lingüistica que no son tratadas adecuadamente y, por tanto, no logran la rehabilitación. Como reconocen Garayzábal y Otero:

Entendemos que para corregir primero hay que evaluar, y para evaluar hay que analizar, y el análisis de algo presupone descripción. Por tanto, para llegar a la corrección, lo primero es la descripción. Los logopedas necesitan disponer de herramientas adecuadas para poder desarrollar su trabajo... El logopeda, responsable de la corrección, necesitará siempre una descripción y un análisis sistemático, cuyo encargado es el lingüista (Garayzábal y Otero, 2005: 178).

Este es el caso del paciente que hemos estudiado, un paciente que se encuentra interno en un centro psiquiátrico por problemas de esquizofrenia paranoide, además de disartria. Al considerarse la esquizofrenia la causa principal (y la única importante) de todos sus problemas, en el centro se ocupan de que el residente se encuentre estable, sin dar importancia a los problemas en el habla que tanto le preocupan. De esta manera, podemos observar que la figura del lingüista clínico es esencial en la actividad terapéutica, ya que ayudaría a muchas personas que necesitan mejorar sus vidas y poderse comunicar adecuadamente, haciendo que se sientan capaces y útiles para la sociedad.

\footnotetext{
22 De hecho, desde los años 90 , se ha registrado un incremento considerable en el número de pacientes que acuden a los servicios hospitalarios por accidentes cerebrovasculares y esto, como reconocen Petheram y Enderby, 2001: 524, puede ser asociado con el creciente reconocimiento del papel del terapeuta del habla y del lenguaje en el abordaje de estas condiciones.
} 


\section{REFERENCIAS}

ACCATINO, S. L. (2012): "Alteraciones del lenguaje en Esquizofrenia”, Revista Memoriza.com, 9, pp. 18.

ALAJOUANINE, M. S. (1956): "Verbal realization in aphasia", Brain, 79, pp. 1-28.

BALL M. J. \& N. MÜLLER (eds.) (2013): Research methods in clinical linguistics and phonetics: A practical guide, Chichester: Wiley-Blackwell.

BARRUECO, J., MÁLAGA, J., GARRIDO, M., GOROSPE, J. \& J. ROQUÉS (1990): “Taxonomía de patologías lingüísticas específicas aceptadas por el Servicio de Foniatria y Logopedia del Hospital Universitario de Salamanca", SOMEF (ed.): Actas del I Congreso Nacional de la Sociedad Médica Española de Foniatría, Salamanca: Sociedad Médica Española de Foniatría, pp. 147-156.

BELINCHÓN, M. (1998): "Esquizofrenia y lenguaje", Ruiz Vargas, J. M. (ed.): Esquizofrenia: un enfoque cognitivo, Madrid: Alianza, pp. 232-258.

BELLOCH, A., SANDÍN, B. \& F. RAMOS (2008): Manual de Psicopatologia, Madrid: McGraw Hill.

CABALLO, V. \& M. A. SIMÓN (2001): Manual de Psicología Clínica infantil $y$ del adolescente, Madrid: Pirámide.

CRYSTAL, D. (1993): Patología del lenguaje, Madrid: Cátedra.

CRYSTAL, D. (2001): "Clinical linguistics", Aronoff, M. y J. Ress-Miller (eds.): The handbook of linguistics, Oxford: Blackwell, pp. 673-682.

DELGADO HERNÁNDEZ，J. (2010): "Inteligibilidad en la disartria atáxica. Estudio de un caso de atrofia olivo-ponto-cerebelosa", Zenker, F. y A. Angulo (eds.):
Actas de la Asociación Española de Audiología. Últimos avances en audiología pediátrica, Santa Cruz de Tenerife: AEDA, pp. 175-180.

DUFFY, J. (2005): Motor speech disorders: substrates, differential diagnosis and management, Filadelfia: Elsebier.

ENDERBY, P. (2013): "Disorders of Communication: Dysarthria", Handbook of Clinical Neurology, Vol. 110, pp. 273-281.

FERNÁNDEZ PÉREZ, M. (2014): "Lingüística y déficit comunicativos", Lingüistica y déficit comunicativos, Madrid: Sintesis, pp. 19-44.

GALLARDO, B. \& B. VALLES (2008): "Lingüística en contextos clínicos: La Lingüística Clínica", Lengua y Habla, 12, 3, pp. 250.

GALLARDO, J. R. \& L. J. GALLEGO (1995): Manual de logopedia escolar, Málaga: Aljibe.

GARAYZÁBAL, E.\& P. OTERO (2005): "Psicolingüística, Neurolingüística, Logopedia y Lingüística Clínica: Juntos sí, pero no revueltos", Filología y Lingüistica, XXXI (1), pp. 163-185.

GOFEMININ.DE GMBH, G. (2017): "Esquizofrenia Síntomas: Delirio, Alucinaciones, Trastornos del yo" - Onmeda.es. [online] onmeda.es. (Available at: http:/ / www.onmeda.es/enfermedades/esquizofrenia-sintomas-1542-5.html.).

GONZÂLEZ, R. A. Y J. A. BEVILACQUA (2012): "Las disartrias", Revista Hospital Clinico Universidad de Chile, 23, pp. 299309.

GOROSPE, J. M., GARRIDO, M., VERA, J. \& J. MÁLAGA (1997): Valoración de la deficiencia y la discapacidad en los trastornos 
del lenguaje, el habla y la voz, Madrid: Ministerio de Trabajo y Asuntos Sociales.

GREEN, P., CARMICHAEL, J \& A. HATZIS (2003): "Automatic Speech Recognition withSparse Training Data for Dysarthric Speakers", Interspeech, pp. 1189-1192.

LABOV, W. (1972): Sociolinguistic Patterns, Filadelfia: Universidad de Pensilvania.

LEÓN-CARRIÓN, J., VIÑALS, F., VEGA, O. Y M. R. DOMÍNGUEZ-MORALES (2001): "Disartria espástica: rehabilitación de la fonación de un paciente con traumatismo cráneo-encefálico", Revista Española de Neuropsicología, 3, 4, pp. 3445.

MÁlAGA, J., GARRIDO, M., GOROSPE, J. M., VELASCO, C. Y R. CASTRO PARENTE (2004): "Revisión taxonómica de los trastornos específicos del desarrollo del lenguaje (TEDL)", Vázquez Ruiz de Larrea, C. (ed.): Trastornos del lenguaje oral, Bilbao: Universidad del País Vasco, pp. 81-93.

MELLE, N. (2003): "Disartria en el daño cerebral adquirido: hacia un método global de evaluación", Revista de Logopedia, Foniatría y Audiología, 23, 1, pp. 20-29.

MELLE, N. (2008): Guia de intervención logopédica en la disartria, Madrid: Síntesis.

MONTFRAGÜE GARCÍA-MATEOS, M. (2010): Análisis de la demanda asistencial en trastornos del lenguaje, habla y comunicación, Salamanca: Universidad de Salamanca.

MUÑOZ-CÉSPEDES, J. M. \& MELLE, N. (2003): "Alteraciones del lenguaje y de la comunicación en adultos con traumatismo craneoencefálico", Puyuelo, M. y J. A. Rondal (eds.): Manual de desarrollo y alteraciones del lenguaje. Aspectos evolutivos y patología en el niño y el adulto, Barcelona: Masson, pp. 435458.

NINDS- NATIONAL INSTITUTE OF NEUROLOGICAL DISORDERS AND STROKE (2012): "Enfermedades de la neurona motora", NINDS. Diciembre 2012. Publicación de NIH 13-5371s.

OTERO CABARCOS P. (2002): “¿Dónde situamos las patologías lingüisticas? Consideración de la Lingüística Clínica como aplicación de la Lingüística”, Bernabé, A., Berenguer, J. A., Cantarero, M. y J. C. De Torres (eds.): Presente y futuro de la lingüistica en España. La sociedad de Lingüistica 30 años después. Actas del II Congreso de la Sociedad Española de Lingüistica, Madrid: SEL, pp. 754759.

PEÑA-CASANOVA, J. (1990): Programa integrado de exploración neuropsicológica - Test Barcelona, Barcelona: Masson.

PEÑA-CASANOVA, J. (2001): Manual de Logopedia, Barcelona: Masson.

PERELLÓ, J. (1990): Trastornos del habla, Barcelona: Masson.

PERKINS, M. Y S. HOWARD (eds.) (1995): Case Studies in Clinical Linguistics, Londres: Whurr Publishers.

PETHERAM, B. \& P. ENDERBY (2001): "Demographic and epidemiological analysis of patients referred to speech and language therapy at eleven centres 1987-95", International Journal of Language and Communication Disorders, 36(4), pp. 515-525.

PICHOT, P. (coord.) (1995): DSM IV: Manual diagnóstico y estadistico de los trastornos mentales, Barcelona: Masson. 
PUYUELO, M. (1998): Logopedia y parálisis cerebral, Barcelona: Masson.

SERRA, E. y M. VEYRAT (eds.) (2005): "Lingüística Clínica y acotaciones epistemológicas", Problemas de eficacia comunicativa. Descripción, deterioro, rehabilitación, Valencia: Universidad de Valencia, pp. 5-19.

THEODOROS, D. G., MURDOCH, B. E. Y H. J. CHANERY (1994): "Perceptual speech characteristics of dysarthric speakers following severe close head injury", Brain injury, 8, 2, pp. 101-124.

TOBIN, Y. (2002): "Phonology as human behabior: Theoretical implications and cognitive and clinical applications", Fava, E. (ed.): Clinical Linguistics: Theory and applications in speech pathology and therapy, Amsterdam/Filadelfia: John Benjamin, pp. 3-22.

URBAN P. P, ROLKE, R., WICHT, S., KEILMANN, A., STOETER, P., HOPF, H. C. et alii (2006): "Lefthesmispheric dominance for articulation: a prospective study on acute ischaemic dysarthria at different localizations", Brain, 129 (3), pp. 767-777.

VAN LANCKER, D. \& N. PACHANA (1998): "The influence of emotion on language and communication disorders", Stemmer, B. y H. A. Whitaker (eds.): The handbook of neurolinguistics, San Diego: Academic Press, pp. 302-313. 